\title{
Demand sensing and digital tracking for maternal child health (MCH) in Uganda: a pilot study for 'E+TRA Health'
}

\section{Dawei Wang}

Purdue University West Lafayette

\section{Rhoann Kerh}

Purdue University West Lafayette

Sungbum Jun

Purdue University West Lafayette

\section{Seokcheon Lee}

Purdue University West Lafayette

\section{Roy Mayega2}

Makerere University

Julius Ssentongo

Makerere University

\section{Andualem Oumer3}

Management Sciences for Health

\section{Md Haque}

University of Indianapolis

\section{Priyanka Brunese}

Purdue University West Lafayette

Yuehwern Yih ( $\nabla$ yih@purdue.edu )

Purdue University West Lafayette

\section{Research Article}

Keywords: demand sensing, healthcare supply chain management, maternal child health $(\mathrm{MCH})$, electronic medical record (EMR)

Posted Date: January 4th, 2021

DOl: https://doi.org/10.21203/rs.3.rs-135785/v1

License: (c) (1) This work is licensed under a Creative Commons Attribution 4.0 International License. 



\section{Demand sensing and digital tracking for maternal child health (MCH) in Uganda: a pilot study for 'E+TRA Health'}

Dawei Wang ${ }^{1}$, Rhoann Kerh ${ }^{1}$, Sungbum Jun ${ }^{1}$, Seokcheon Lee ${ }^{1}$, Roy William Mayega ${ }^{2}$, Julius Ssentongo $^{2}$, Andualem Oumer ${ }^{3}, \mathrm{Md} \mathrm{Haque}^{4}$, Priyanka Brunese ${ }^{1,5}$, Yuehwern Yih ${ }^{1,5,6^{*}}$

${ }^{I}$ School of Industrial Engineering, Purdue University, West Lafayette, IN 47907, USA

${ }^{2}$ School of Public Health-Resilient, Africa Network (RAN), Makerere University, Kampala, Uganda

${ }^{3}$ Management Science for Health, Medford, MA 02155, USA

${ }^{4} R$ B Annis School of Engineering, University of Indianapolis, Indianapolis, IN 46227, USA

${ }^{5}$ LASER PULSE (Long-term Assistance and SErvices for Research, Partners for University-Led Solutions

Engine) Consortium, Purdue University, West Lafayette, IN 47907, USA

${ }^{6}$ Regenstrief Center for Healthcare Engineering, Purdue University, West Lafayette, IN 47907, USA

*Corresponding author. Email: yih@purdue.edu, Address: 315 N. Grant Street, West Lafayette, IN 47907

\section{Abstract}

\section{Background}

The Electronic tracking system for healthcare commodities (E+TRA Health) is an all-in-one outof-box solution for supply chain management system of healthcare commodities for lower-level health facilities in rural areas. It aims to support real-time monitoring and decision-making to (1) reduce the time needed to prepare orders, (2) reduce stockout and overstock cases of targeted medical supplies, (3) help improve patient outcomes. In this study, we adopted an integrated approach to analyze the process of information flow, identify and address critical paths of essential supplies associated with maternal health in the Ugandan health system.

Methods

We apply system engineering principles and work with community partners in hospitals to develop care process workflow charts (based on essential services) for the lifecycle of maternal health continuum of care. Based on this chart, we develop a local cloud-based offline-compatible smart sync platform named "E+TRA Health" to triangulate 1) patient admission, diagnoses, delivery information, testing reports from laboratories, 2) inventory information from main store, stores in Maternal Child Health (MCH) unit, and 3) lab, to identify the critical list of medical and laboratory supplies, their lead times for procurement and then generate reports and suggested procurement plans for real time decision-making.

Results

The E+TRA Health platform was piloted in two Healthcare Center IV facilities in Uganda over a period of 6 months. The system collected more than 5,000 patient records and managed more than 500 types of medicines. The pilot study demonstrated the functionalities of E+TRA Health and its feasibility to sense demand from point of care.

Conclusion

$E+T R A$ Health is the first to triangulate supply and demand data from three different departments (main store, lab, and MCH) to forecast and generate orders automatically to meet patient demands. It is capable of generating reports required by MOH in real time compared to one-week 
lead-time using paper-based systems. This prompts frontline stakeholders to generate efficient, reliable and sustainable strategic healthcare plans with real time data. This system improves patient outcomes through better commodity availability by sensing true patient demands.

Keywords: demand sensing, healthcare supply chain management, maternal child health (MCH), electronic medical record (EMR)

\section{Background}

\section{Introduction}

Every two minutes, a preventable death occurs during childbirth in developing countries. Complications from pregnancy and childbirth are the leading cause of death among girls aged from 15-19 [1,2]. Inadequate inventory and supplies contribute significantly to preventable death in low and middle income settings [1,3-5]. UN Commission on Life-Saving Commodities for Women and Children identified and endorsed an initial list of 13 overlooked life-saving commodities that could save the lives of more than 6 million women and children, if more widely accessed and properly used [6].

A system to capture the consumption and needs of Maternal Child Health $(\mathrm{MCH})$ commodities at each health facility is needed to guarantee high levels of service and minimize stockouts [7]. Many healthcare systems in Uganda implement standardized data registers to capture patient information and health product inventory status. However, in some lower level health facilities (e.g., Healthcare Center IV), limited computer resources prevent digitizing up-to-date recordkeeping [8]. Consequently, there is no digital data management system to capture information about product consumption and inventory. Staff at these healthcare facilities manually collect information from multiple paper-based registers. The main challenge for these paper registries is that health workers do not have consistent standards in maintaining records which makes accurate data capture impossible and hard to support real time decisions $[9,10]$. At the district level, lack of patient registers, stock cards, and lab results brings barriers for stakeholders to make evidence-based commodity orders. Long resupply intervals aggravate stockout and expired medication problems [7]. Lack of coordination and human errors cause delays and waste resources, weakening responsiveness of the healthcare supply chain and putting patients at risk.

Therefore, this article presents a demand sensing and digital tracking system that was piloted to analyze information flow and address critical paths of supplies associated with $\mathrm{MCH}$ in the Ugandan health system. Three datasets were redesigned and digitized: (1) MCH Unit: Patient Admission, Diagnosis, Delivery, Prescription, Lab Results; (2) Main store: Goods Delivery, Receiving; and (3) Laboratory: Commodity Dispensing, Daily Activity Report. Functions such as item coding, generation of monthly reports directly from the system, and generation of automatically suggested procurement orders were introduced. We implemented this system in two pilot sites at Kojja and Mukono Healthcare Center IV facilities in Uganda. Lists of supplies needed throughout the lifecycle of MCH continuum of care are studied based on 6 months data.

\section{Healthcare Delivery Systems}

Information of Healthcare delivery is usually captured in two independent systems: health information system and healthcare supply chain management system. Health information system is typically known as the electronic medical record system (EMR), and collects health information about the patients, such as medical history. While, healthcare supply chain management system logs the dispensing of healthcare commodities, monitors inventory levels 
and restocks? replenishments. The following sub section presents the health information and health supply chain management systems in the context of the Ugandan health system.

\section{- Health information system in Uganda}

Uganda health governance is divided into regions, districts, sub-districts, health facilities, and villages [11]. Accordingly, the health services are structured into National Referral Hospitals (NRHs) and Regional Referral Hospitals (RRHs), General Hospitals, Health Center (HC) IVs, HC IIIs, HC IIs and Village Health Teams (HC Is). At the highest level, NRHs, RRHs, and Genral Hospitals provide specialist clinical and comprehensive services. At the secondary district level, HC IIIs offer basic preventive, promotive and curative care. HC IIs only provide outpatient care and community outreach services. At the lowest level, Village Health Teams (VHTs)/HC Is facilitate health promotion, service delivery, and community participation [11].

Uganda's first Health Information System (HIS) was designed in 1985 to capture and analyze data on communicable and non-communicable diseases [8][12]. A centralized health management information system (HMIS) was introduced in 1993 that focused on morbidity and mortality reporting, collecting data from health units to the districts and national levels [13][14]. The HMIS was completely paper-based. Monthly reports were generated from VHTs at the lowest level and submitted to HCs. HCs aggregated and submitted reports to District Health Office (DHO). DHOs compiled reports and submitted to MoH. This cumbersome monthly reporting process that required health workers lots of time to tally by going through logs often results in inaccurate data [14]. There are also other HIS tools, such as "mTrack", a SMS-based HMIS tool designed to report on disease surveillance, "WinSenga", a fetal heart rate monitor using smartphones (ibid), etc. Various HIS interventions emerged in Uganda but often ended in pilot phases due to lack of clear evaluation or limited skills, inadequate policy and low adoption by health workers [12].

Just like in many developing countries, Uganda's health system recognizes the benefits of electronic medical record (EMR) systems [15 - 18], mobile health [19, 20], and risk surveillance systems [21, 22]. However, limited infrastructure and resources hinder the design and implementation of these systems. In addition, current EMR systems in developing countries including Uganda scarcely address the needs of $\mathrm{MCH}$, mostly focusing on large-scale treatments of diseases like HIV and tuberculosis. (i.e., Uamuzi Bora Kenya [23], PIH-EMR Peru [24], HIVEMR Haiti [25], OpenMRS Uganda [26], Lilongwe EMR Malawi [27]).

\section{- Healthcare supply management system}

Although some EMR systems are increasingly amenable to monitor and integrate maternal and child health services in developing countries [28], few studies have addressed the application of EMR in inventory management [8, 29]. Tracking medicines, supplies and lab reagents in developing countries including Uganda is still paper-based stock books/stock cards/dispensing logs. This analog and manual tracking leads to difficulty in recording transactions in real time and requires tremendous effort and time to compile information. Duplications and errors of information make it difficult for store managers to prepare accurate consumption reports to generate right orders. Also, lack of coordination between $\mathrm{MCH}$ units and the main store causes difficulties in future demand/order forecasting [30,31]. This results in stockout or overstock issues, which jeopardize the access to specific medical supplies, thus impacting survival and safety of pregnant women and their newborns. Therefore, there is a need for a digital healthcare supply management system that is tailored to meet $\mathrm{MCH}$ patient needs. Thus, in resource limited settings like Uganda, 
evidence based, coordinated, accurate stock management and quantification can prevent dangerous stockouts of health products. Also, precise ordering requires integration of quantification, EMR, dispensing and inventory control.

Several computerized systems need to be combined for a healthcare supply chain system EMR systems record patient history, medicine regimens and dosages. Dispensing systems record health products dispensed (i.e., mSupply, iDart, RxSolution, ADT). Inventory control systems track individual supplies by names, batch numbers, stock quantities and expiration dates (i.e., SIGMED, ORION, mSupply, HIV-EMR Pharmacy system, Navision, Syspro, ePICs). Quantification systems assist in calculating budget requirements and order quantities (i.e., FoCaMed, Quantimed, RxSolution, PIH-EMR, MSF ARV Drug Order Tool). However, EMR, Inventory control, and Dispensing systems manage patient data, inventory data and dispensing data separately. Moreover, all these tools have been mainly applied at the national and/or regional/state levels, not at the clinical level. Therefore, there is no all-in-one solution that has the capability to integrate all demand and supply data together to suggest a procurement plan at the clinical level.

Despite substantial needs, very few software systems are actually effective in resource scarce environments. Current limitations include: (1) None of the current systems combine the EMR, inventory control, dispensing and quantification systems. (2) Not all datasets are considered when preparing order quantities, which diminishes accuracy of order data due to the lack of cross-data checking. (3) System designs are large, complex and tailored for national warehouses or retail pharmacies. (4) Most systems are closed-source, making customization and technical support difficult and costly. (5) Systems are designed with the assumption that high-bandwidth networks are available. (6) Systems are designed without considering the need to quantify and enter data on other supplies such as test and lab regiments.

\section{Methods}

Healthcare information systems struggle in developing countries due to limited infrastructure and resources. Many of them require high-bandwidth connections. The system we proposed is an allin-one solution that can be used without access to the Internet. We created a local network that can exchange information within each facility. The system is a local cloud-based system coded in PHP, HTML, JavaScript, and CSS backed with SQL databases.

\section{Step 1: Site Selection}

The study was conducted in Mukono district, Uganda. The district is located in the central region of Uganda, with a population of 596,804 people (UBOS, 2014). Mukono district has a total of 51 health facilities that are points of delivery for primary health care, and these include: one general hospital, three health center IVs, 15 health center IIIs, and 32 health center IIs. Our study was conducted in two health center IVs, namely Mukono and Kojja. We selected these two health facilities as they represent primary health care seeking behaviors and other dynamics at both urban/peri-urban and rural settings. Mukono HC IV represents an urban public health facility setting and it conducts over 500 deliveries per month. On the other hand, Kojja HC IV is situated

in a rural setting which is similar to many of Uganda's PHC facilities. It conducts about 100 deliveries per month.

\section{Step 2: Understanding Issues Facing Health Practitioners in Selected Sites}


This study used an iterative co-design process among academics, practitioners, and other stakeholders, which evolves to the Embedded Research Translation (ERT) model ${ }^{\dagger}$, co-developed by USAID and LASER PULSE consortium, where research is intentionally applied to a development challenge. It has similar characteristics to Integrated Knowledge Translation (IKT), which is also a collaborative research approach involving health practitioners as equal partners alongside researchers, with the goal of creating more relevant and useful solutions that result in better research outcomes [32, 33, 34, 35]. The key principle of both ERT and IKT is involving practitioners throughout the research process starting with identification of the research question, and are actively engaged in the governance, priority setting and conduct of the research [32].

IKT is used specifically in public health intervention research [36] in Canada, with the assumption that it can increase the uptake of research evidence into policy and practice as the collaboration process between researchers and practitioners will generate knowledge that is relevant to practitioners $[32,37,38]$. IKT was established by the Canadian Institute of Health Research (CIHR) and has evolved from traditional 'Knowledge Translation' approaches which goes beyond the reductionist view of knowledge translation that typically involves 'translating' research findings at the end-of-the-grant research by filling the gap with 'translated products for dissemination'; to co-producing knowledge for 'actionable evidence'.

The ERT model was developed for the field of international development. It is a new approach that consists of four pillars: partnership, process, product and dissemination. Through partnership, partners are integrated early and throughout the project for solutions more likely to be adopted and applied. Thus, researchers including a team from Makerere University School of Public Health-Resilient Africa Network (RAN) engaged and partnered with the health practitioners at Kojja Health Center IV and Mukono District Health Office, Mukono Health Center IV facilities in Uganda. The second pillar of the ERT model is a process to ensure a solid foundation to work together effectively. Thus, meetings were conducted to establish collaboration and to understand the specific needs of the key stakeholders. The third pillar for ERT is the translated product which is co-designed to inform policy and/or practice. Thus, including the end users of the system was a critical step in identifying and prioritizing the system requirements; and then design the system accordingly. The research team was able to understand the current patient care and data management system as a result of this process. For example, the team learned that it took 2-3 days to prepare a bi-monthly order and a week to prepare a monthly report required by the Ministry of Health $(\mathrm{MOH})$ of Uganda. The team learned that there was duplicate data being recorded in different hand-written registers. Also, order quantities for medical supplies were being estimated based on existing stock levels instead of patient needs. These issues were creating issues in commodity management which were impacting effective patient care. These learnings were used as an input to the way in which the system was designed. The last pillar for the ERT model is dissemination, and plan for wider application and scale-up beyond the partnership and toward a larger uptake in the field or region. This was a limitation of the study and findings around this are further discussed in the sections below.

† LASER PULSE, https://stemedhub.org/groups/laserpulse/our-work/r2t 


\section{Step 3: Development of System Requirements}

The all-in-one healthcare supply chain management system tailored for $\mathrm{MCH}$ unit that we propose needed to triangulate supply chain, patient, lab dispensing data all together to fulfil the following three requirements of each sector listed in Table. 1:

\begin{tabular}{|c|c|c|}
\hline Sector & Function & Requirements \\
\hline \multirow{5}{*}{$\begin{array}{l}\text { Supply Chain } \\
\text { Management } \\
\text { (SCM) }\end{array}$} & Sourcing & $\begin{array}{l}\text { Once the commodities from the national medical store arrive at the } \\
\text { healthcare facility, record item details such as names, quantities, } \\
\text { expiry dates, arrival times. }\end{array}$ \\
\hline & Item Coding & $\begin{array}{l}\text { Assign unique codes to identify commodities so that users can easily } \\
\text { pull-out records for each item for detailed analysis and audits. }\end{array}$ \\
\hline & Dispatching & $\begin{array}{l}\text { Capture quantities of products dispatched to wards such as the } \mathrm{MCH} \\
\text { unit and the lab. Record logs of dispensed commodities to capture } \\
\text { consumption rates. }\end{array}$ \\
\hline & $\begin{array}{l}\text { Inventory } \\
\text { Management }\end{array}$ & $\begin{array}{l}\text { Capture up-to-date sourcing and dispensing records. Aggregate logs } \\
\text { to generate monthly transaction reports. Let warehouse managers } \\
\text { manually override and adjust inventory levels and record it with } \\
\text { reasons to keep transparency. }\end{array}$ \\
\hline & $\begin{array}{l}\text { Determination of } \\
\text { order quantities }\end{array}$ & $\begin{array}{l}\text { Suggest order quantity for each health product. Store managers can } \\
\text { refer to the suggested order. Forecasted order quantities generated } \\
\text { can be used directly as the order. }\end{array}$ \\
\hline \multirow{2}{*}{$\begin{array}{l}\text { Electronic } \\
\text { Medical Record } \\
\text { (EMR) }\end{array}$} & Patient Record & $\begin{array}{l}\text { Contains all information about the patient, such as admissions, } \\
\text { prescriptions, diagnoses, lab results, antenatal records, and } \\
\text { deliveries. Prescriptions are used to calculate consumption rates of } \\
\text { health products. }\end{array}$ \\
\hline & $\begin{array}{l}\text { Ministry of Health } \\
\text { (MOH) Monthly } \\
\text { reports }\end{array}$ & $\begin{array}{l}\text { Generate monthly reports in standardized formats as required by } \\
\text { Uganda } \mathrm{MOH} \text {. }\end{array}$ \\
\hline \multirow[t]{2}{*}{$\begin{array}{l}\text { Demand } \\
\text { Sensing } \\
\text { Integration }\end{array}$} & Lab dispensing log & $\begin{array}{l}\text { Besides EMR (patient data) and SCM (inventory data), record daily } \\
\text { activities in the labs: number of tests and patients, number not } \\
\text { performed due to lack of supplies, and quantity of supplies and } \\
\text { reagents used. }\end{array}$ \\
\hline & Integration & $\begin{array}{l}\text { Triangulate consumption and sourcing data from labs, stores, and } \\
\text { MCH units with patient data to forecast and generate purchase } \\
\text { orders automatically. }\end{array}$ \\
\hline
\end{tabular}

Table 1. System requirements

\section{Step 4: Development of System Architecture}

The proposed architecture uses a cloud-based centralized database (Fig. 1). Data collection is done on Android tablets using an open-source application, OpenDataKit. Compared to computers/laptops, tablets are cheaper and more portable. They have longer battery lives, lasting more than 10 hours. This is critical in places with limited power resources. Multiple tablets can be issued to enter data simultaneously. They are all connected to a local wi-fi network via multiple routers that cover different departments/wards. Data collected on those Android tablets are pushed automatically to the centralized SQL database located in a laptop. The laptop is hosting a web server with SQL database, and an OpenDataKit server using Apache TomCat. Data is then visualized on a website that is accessible from any device connected to the wi-fi network. The routers can be connected to a $4 \mathrm{G}$ modem to connect to the Internet, so that we can remotely troubleshoot the system and access reports via TeamViewer or other remote-control 
applications.

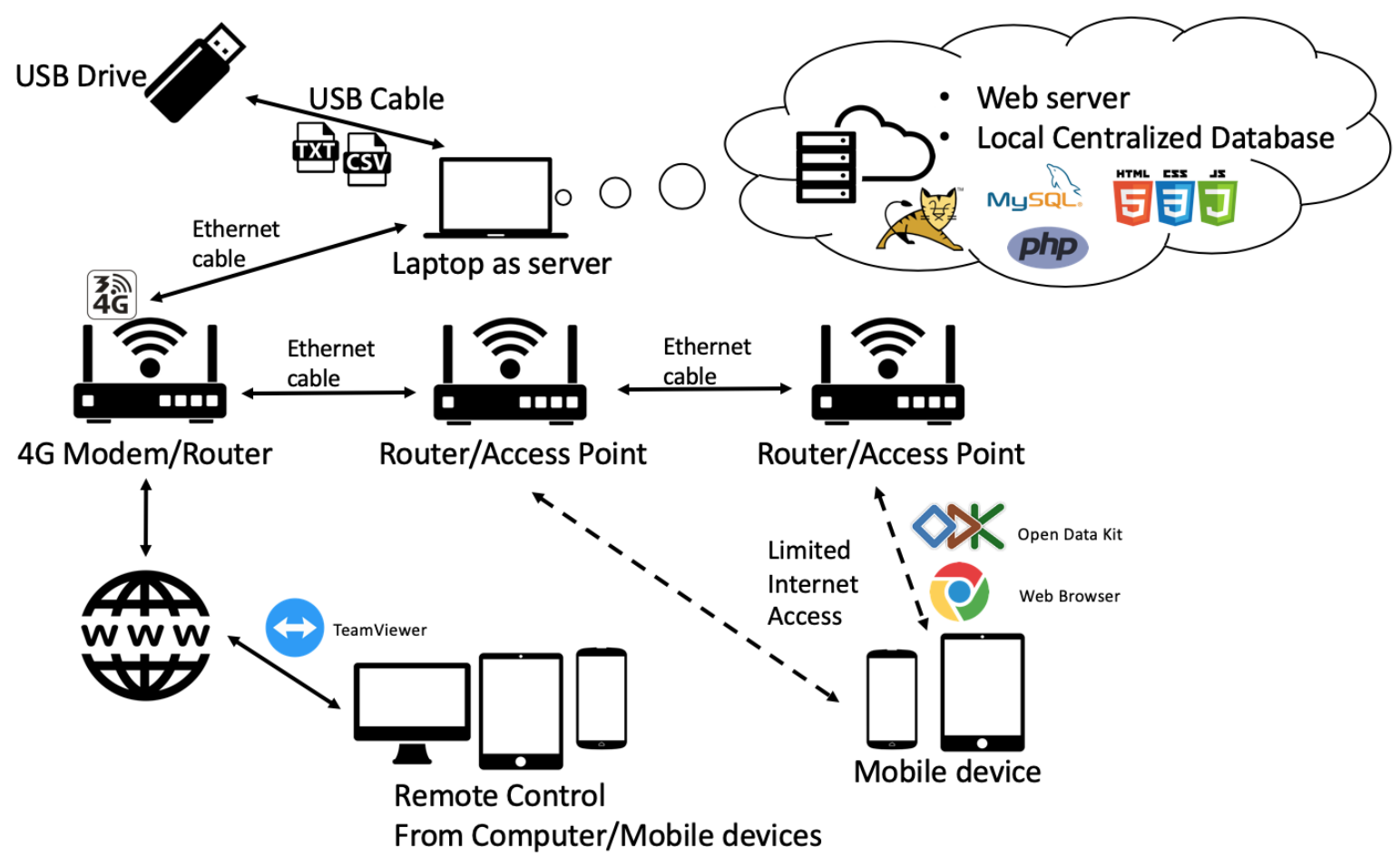

Fig. 1. Architecture

\section{Key Features of E+TRA Health System}

Key features of E+TRA Health system are listed in the Table. 2 to fulfil the system requirements listed in Table. 1.

\begin{tabular}{ll} 
Feature & Detail \\
\hline Cloud-based & $\begin{array}{l}\text { Any device with a web browser can use this system, including computers, smart } \\
\text { phones, and tablets, with no installation or software updates. All maintenance and } \\
\text { updates are done at the server side. }\end{array}$
\end{tabular}

\section{Coded in open source language}

\section{Offline-compatible}

\section{Cross-platform Transparency \\ Automatic report generation}

The website is coded in an open-source language, PHP, which is relatively easy to develop and maintain. As of 2019, 79\% of all server-side websites use PHP [39]. And it is the most-used open source software within enterprises [40].

In developing countries, different departments of a healthcare facility are quite far from each other. Some locations are not covered by wi-fi signals. There are power outages that shut down the routers. Open-source data collection software (e.g., OpenDataKit) provides offline function (Fig. 2). Data is stored locally on the devices not covered by wi-fi signals and is uploaded and synchronized automatically when they get access to the local network.

Accessible in different operating systems, e.g., Windows, Mac OS, Android, iOS, etc. Track any item from receiving from national/district medical stores to dispensing to patients. All transactions/movements and manual adjustments are recorded.

Generate monthly standardized reports in real time, which are required to submit to the Ministry of Health of Uganda every month, would take one week for staff to manually 
generate (Fig. 3). Visualize data collected (Fig. 4) to support decision making.

Full patient record

Automatic inventory level updates

\section{Generation of order quantities}

Once admitted during their first visit, future visit histories will be connected automatically via patient ID that is assigned.

Supply data is extracted from the sourcing forms. Consumption data is extracted from patient prescriptions and lab activities. Store managers no longer manually update and track stock levels on paper or spreadsheets. Full history of transactions of each commodity is recorded in the system and visualized (Fig. 5).

Triangulates data collected from $\mathrm{MCH}$, lab, and main store to forecast the order quantities to the national store, based on maximum stock levels of the health facility.

Table. 2 Key features of E+TRA Health system

Integrated Maternity Register Prescription Info

* The date to fill the form

Oct $08,2019,22: 30$

* Patient ID

* Tetanus Dose Given

* IPT/CTX

* Menbendazole-Dose

* IRON Provided

* Vitamin A Supplementation Provided

Go Up Go To Start Go To End

Fig. 2 Example mobile device form 
HMIS FORM 072a: MATERNITY TALLY SHEET

Report for 03-2019

\begin{tabular}{|c|c|}
\hline \multicolumn{2}{|l|}{ ADMISSIONS } \\
\hline ADMISSIONS & 68 \\
\hline \multicolumn{2}{|l|}{ REFERRALS } \\
\hline REFERRALS TO MATERNITY UNIT & 0 \\
\hline REFERRALS OUT FROM THE MATERNITY UNIT & 0 \\
\hline \multicolumn{2}{|l|}{ DELIVERIES IN UNIT } \\
\hline DELIVERIES IN UNIT AMONG THE WOMEN AGED 10-19 YEARS & 2 \\
\hline DELIVERIES IN UNIT AMONG THE WOMEN AGED 20-24 YEARS & 5 \\
\hline DELIVERIES IN UNIT AMONG THE WOMEN AGED > =25 YEARS & 6 \\
\hline FRESH STILL BIRTH & 0 \\
\hline MACERATED STILL BIRTH & 0 \\
\hline LIVE BIRTHS & 13 \\
\hline \multicolumn{2}{|l|}{ WOMEN TESTED FOR HIV IN LABOUR } \\
\hline WOMEN TESTED FOR HIV IN LABOUR FOR THE 1ST TIME PREGNANCY & 10 \\
\hline WOMEN TESTED FOR HIV IN LABOUR DURING A RETEST THIS PREGNANCY & 0 \\
\hline WOMEN TESTING HIV+ IN LABOUR FOR THE 1ST TIME PREGNANCY & 0 \\
\hline WOMEN TESTING HIV+ IN LABOUR DURING A RETEST THIS PREGNANCY & 0 \\
\hline \multicolumn{2}{|l|}{ HIV+ WOMEN INITIATING ART IN MATERNITY } \\
\hline HIV + WOMEN INITIATING ART IN MATERNITY & 0 \\
\hline \multicolumn{2}{|l|}{ DELIVERIES TO HIV+ WOMEN IN UNIT } \\
\hline DELIVERIES TO HIV+ WOMEN IN UNIT & 2 \\
\hline LIVE BIRTHS TO HIV+ WOMEN IN UNIT & 2 \\
\hline \multicolumn{2}{|l|}{ HIV-EXPOSED BABIES GIVEN ARVS } \\
\hline HIV-EXPOSED BABIES GIVEN ARVS & 2 \\
\hline \multicolumn{2}{|l|}{$\begin{array}{l}\text { MOTHERS WHO INITIATED BREASTFEEDING WITHIN THE FIRST HOUR } \\
\text { AFTER DELIVERY }\end{array}$} \\
\hline $\begin{array}{l}\text { TOTAL NO. OF MOTHERS WHO INITIATED BREASTFEEDING WITHIN THE FIRST } \\
\text { HOUR AFTER DELIVERY }\end{array}$ & 13 \\
\hline $\begin{array}{l}\text { NO. OF HIV+ MOTHERS WHO INITIATED BREASTFEEDING WITHIN THE FIRST } \\
\text { HOUR AFTER DELIVERY }\end{array}$ & 2 \\
\hline \multicolumn{2}{|l|}{ BABIES BORN WITH LOW BIRTH WEIGHT ( $<2.5 \mathrm{KG})$} \\
\hline BABIES BORN WITH LOW BIRTH WEIGHT $(<2.5 \mathrm{KG})$ & 0 \\
\hline \multicolumn{2}{|l|}{ LIVE BABIES } \\
\hline LIVE BABIES & 13 \\
\hline \multicolumn{2}{|l|}{ BABIES BORN WITH DEFECT } \\
\hline BABIES BORN WITH DEFECT & 0 \\
\hline \multicolumn{2}{|l|}{ MOTHERS GIVEN VITAMIN A SUPPLEMENTATION } \\
\hline MOTHERS GIVEN VITAMIN A SUPPLEMENTATION & 0 \\
\hline \multicolumn{2}{|l|}{ MATERNAL DEATHS IN WOMEN } \\
\hline MATERNAL DEATHS IN WOMEN AGED 10-19 YEARS & 0 \\
\hline MATERNAL DEATHS IN WOMEN AGED 20-24 YEARS & 0 \\
\hline MATERNAL DEATHS IN WOMEN AGED $>=25$ YEARS & 0 \\
\hline \multicolumn{2}{|l|}{ BORN BEFORE ARRIVAL (BBA) } \\
\hline BORN BEFORE ARRIVAL (BBA) ALIVE & 0 \\
\hline BORN BEFORE ARRIVAL (BBA) DEAD & 0 \\
\hline
\end{tabular}

Fig. 3 Generated HMIS printable form 

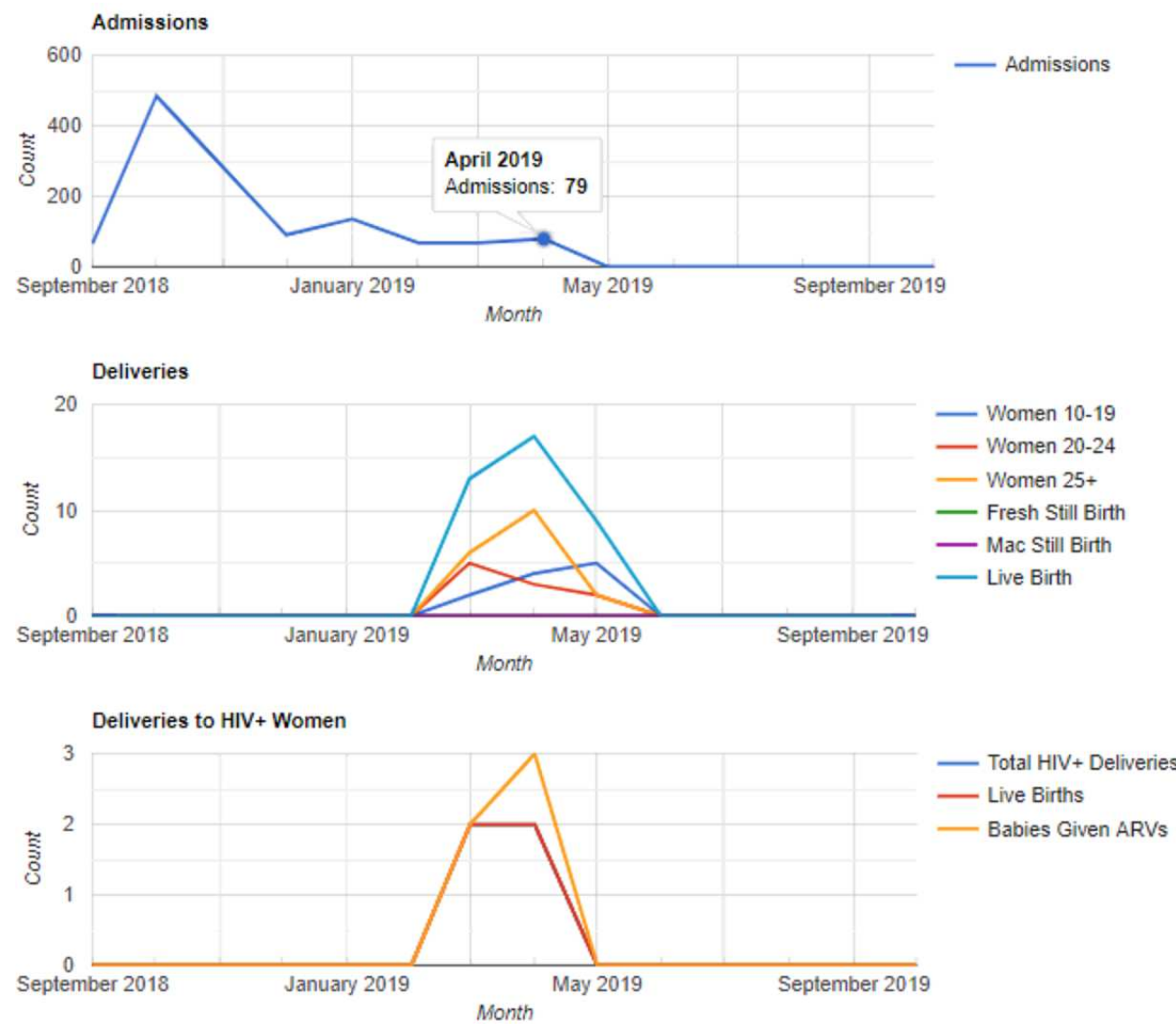

Fig. 4 Generated plots

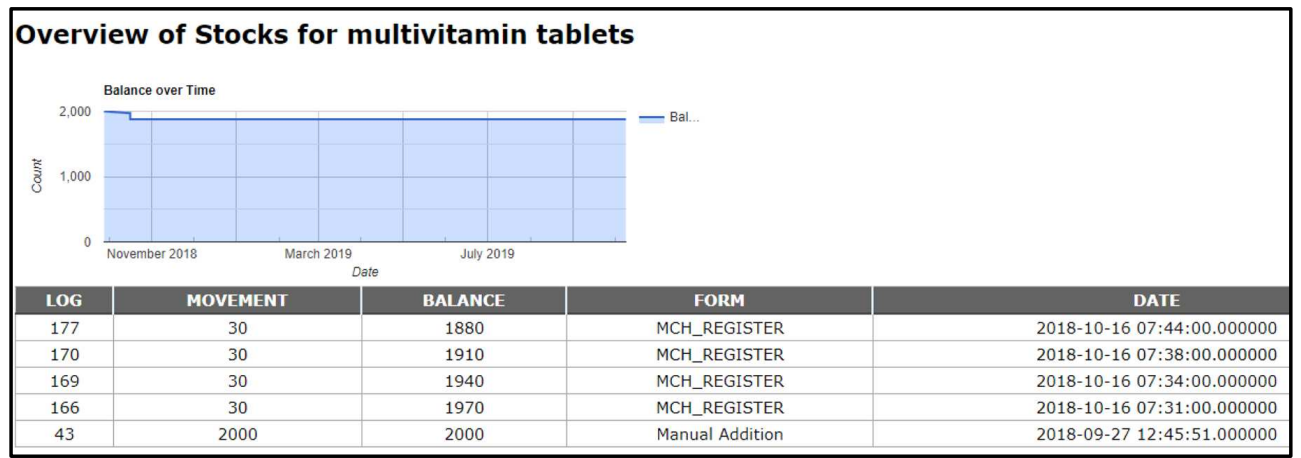

Fig. 5 Full history of transactions of each commodity

\section{Step 5: Integrating System with Practitioner Workflow}

To tailor for the $\mathrm{MCH}$ unit, we have reevaluated the needs of users and redesigned forms and 
users' workflow.

- Main store: good receiving note and good delivery note.

The system was integrated with the 'main store' workflow by the development of the 'notes feature'. The good receiving note was used to record what items have been received from the national/district medical store, while the good delivery note was used to record what has been dispatched to the $\mathrm{MCH}$ unit and the lab. The main store manager was in charge of completing these two forms. Inventory levels in the main store, lab, and $\mathrm{MCH}$ are updated automatically, so the main store manager did not need to manually update the inventory levels.

\section{- MCH unit:}

The system was integrated with the $\mathrm{MCH}$ unit workflow by the development of patient forms such as the Admission form, the diagnosis form, the lab report, the prescription form, and the delivery form replace HMIS form 071 (Antenatal Register) and HMIS form 072 (Integrated Maternity Register) (see Fig. 6).

To improve workflow in digital forms, two paper-based forms were separated into five digital forms, since fields are filled at disjoint times: admission, lab result, doctor's diagnosis, prescription issued, and delivery. All five forms were connected via the patient ID. Therefore, the information was filled exactly and only once. Entire patient history was tracked via patient ID. Inventory levels were deducted automatically upon submission of prescription forms.

\section{HMIS FORM 071: INTEGRATED ANTENATAL REGISTER}

COLUMN HEADINGS:
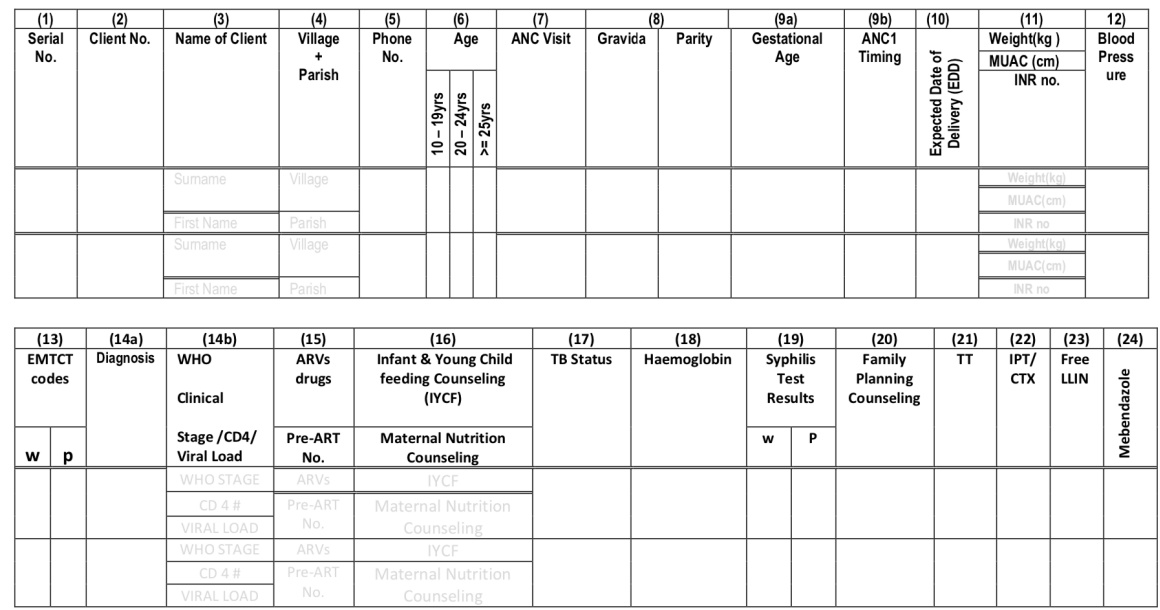

\begin{tabular}{|c|c|c|c|c|}
\hline \multicolumn{2}{|c|}{ (25) } & (26) & (27) & (28) \\
\hline \multicolumn{2}{|c|}{ Iron/Folic Acid } & & Referralun/Out & Pisk Earors/Comnlications \\
\hline $\mathrm{Fe}$ & Folic & & 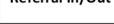 & \\
\hline & & & & \\
\hline & & & & \\
\hline
\end{tabular}



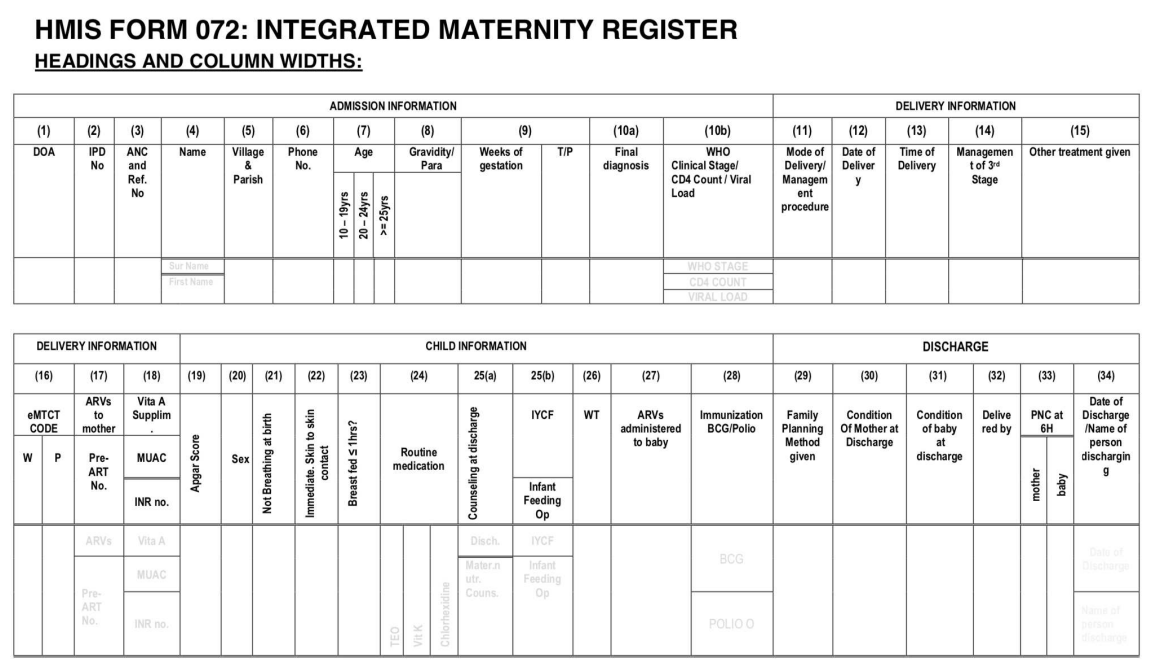

Fig. 6. HMIS Forms: Integrated Antenatal Register and Integrated Maternity Register

- Lab:

The system was integrated with the Lab workflow by the development of two forms to estimate commodity usage. The lab commodity dispensing form captures dispensing information of lab products. Lab products come in large volume bottles for multiple tests. It is difficult to count how many drops are used during each test. The form was designed to be filled when one countable unit of quantity is used, such as one bottle. The lab daily activity report captured the number of tests and patients served daily.

\section{Step 6: Design of Information Flow}

With redesigned forms, inventory levels were updated automatically upon submission of patient prescription form, lab dispensing log, and good delivery note (Fig. 7). Stock reports such as inventory levels, monthly movements, transaction details, and discrepancy reports, were generated automatically. The predictive model learns from consumption and supply data to forecast and generate orders for the national store. 


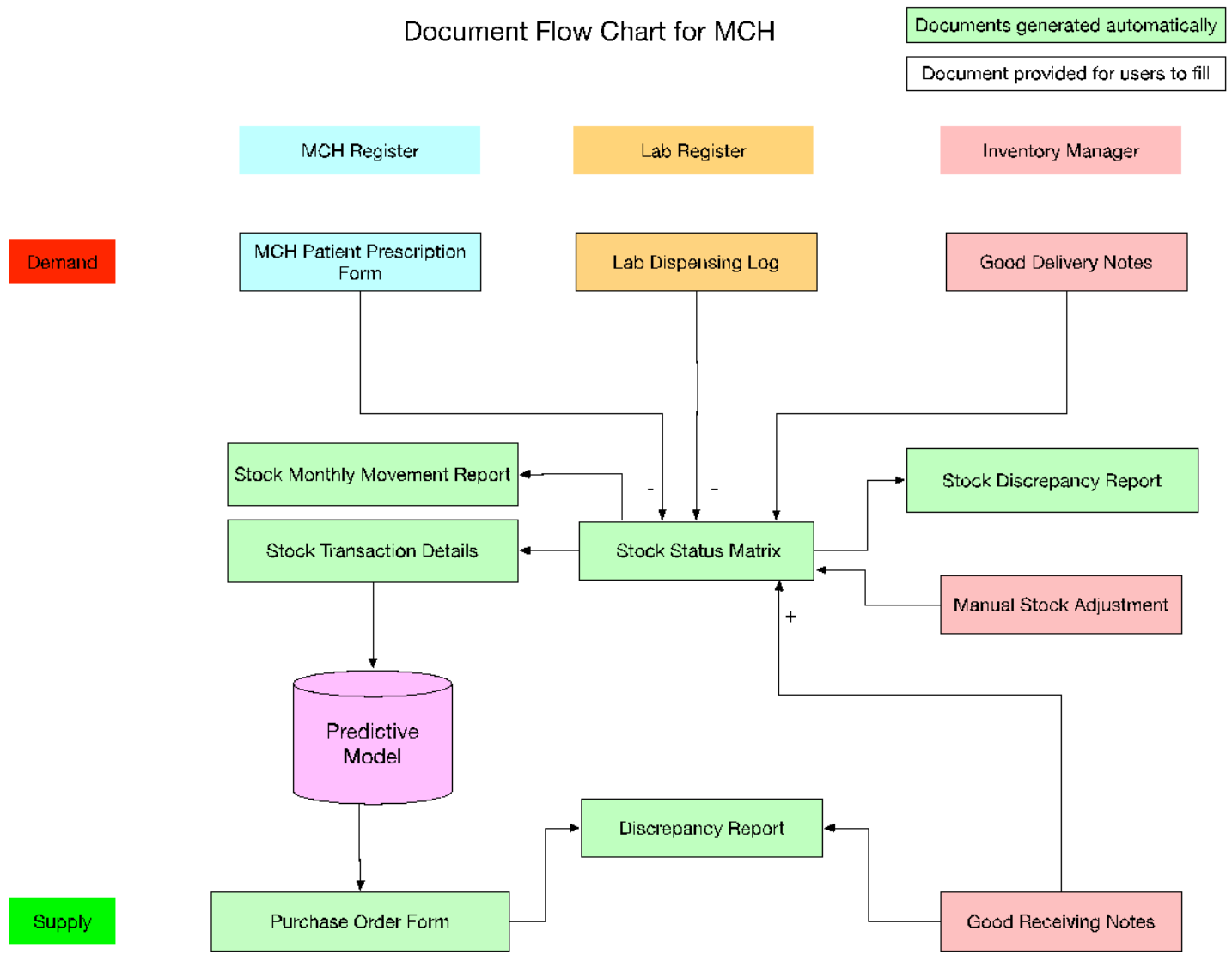

Fig. 7 Document flow for $\mathrm{MCH}$

\section{Step 7: System Testing and Deployment}

Assembled, transported and tested before deployment

We deployed two sets of equipment during our 2nd visit on Sept. 23-29, 2018 :

- Mukono Health Center IV: laptop, router, wi-fi extender, 8 tablets.

- Kojja Health Center IV: laptop, router, wi-fi extender, 5 tablets.

Main store, lab and $\mathrm{MCH}$ units - one tablet for each, with an extra for backup. Both facilities encountered wi-fi signal strength issues. At Mukono, the delivery room is far from the nearest extender. There was no extra outlet in the $\mathrm{MCH}$ unit to install another wi-fi extender. At Kojja, lab and $\mathrm{MCH}$ are too far from the router that was installed in the server room powered by solar panel and located in a different building. We installed powered access point with wires extended to the $\mathrm{MCH}$ unit.

We revisited those two facilities five months later in March 2019.

\section{Results}

\section{Summary of Data Collected from System Deployment}

We implemented this system in two health facilities in Uganda: Kojja and Mukono HC IV over 6 months. In Mukono, a larger site with more patients, patient admission forms were 
mostly filled using the new system, leaving us only basic information such as name, age, and village. In Kojja, more forms were filled but counts are lower than expected due to an unstable network caused by construction and power outages. Overview of data collected from the two facilities over 6 months is listed in Table. 3 .

\begin{tabular}{llrr}
\hline Department & \multicolumn{1}{c}{ Forms } & Koija HC IV & Mukono HC IV \\
\hline \multirow{3}{*}{ MCH } & Patient Admission & 1275 & 4417 \\
& Patient Diagnosis & 104 & 6 \\
& Patient Prescription & 906 & 43 \\
& Patient Delivery & 39 & 0 \\
& Patient Lab Tests & 252 & 11 \\
\hline \multirow{2}{*}{ Lab } & Lab dispensing report & 3 & 0 \\
& Lab activity report & 16 & 0 \\
\hline \multirow{2}{*}{ Main Store } & Main store receiving form & 9 & 0 \\
& Main store distribution form & 0 & 1 \\
\hline
\end{tabular}

Table. 3 Data overview

\section{Predictive model}

To improve the demand forecasting of medical supplies, predictive models were developed in this study based on the data collected from the system. Due to the time constraint of data collection, not all the medical products and their trend can be captured in the short data collection time frame. Health products were classified into three types based on the amount of past data, by which we will select appropriate prediction methods.

- Type 1: Demand forecasting is not applicable due to the lack of previous consumption data

- Type 2: Demand forecasting for immediate future is possible with limited consumption data

- Type 3: Demand forecasting for an extended period of time is possible with sufficient consumption data

Three predictive models were developed for the three different types of health products based on the amount of available previous consumption data. For type 1 products, the minimum required amount and budget limit are directly used without actual past data to determine order quantities. Table 4 presents the health products and their predicted demands determined by aggregating responses from experts without actual data. 
For type 2 health products, average monthly consumptions are used to forecast the demand for the next month as the data accumulated possess information needed to derive average demand. It was observed that only 5 items in the collected data have more than 1-month demand. Table 5 shows the type 2 products and their predicted demands determined by averaging the consumption data over a certain period (e.g., 3-4 months).

\begin{tabular}{|c|c|c|c|c|}
\hline $\begin{array}{l}\text { Item } \\
\text { ID }\end{array}$ & Item Name & $\begin{array}{l}\text { Actual } \\
\text { Demand }\end{array}$ & $\begin{array}{l}\text { Predictive } \\
\text { Demand }\end{array}$ & Ven Scale \\
\hline 1 & Artemether/ Lumefantrine $120 \mathrm{mg}$ tablet & 22 & 30 & Vital \\
\hline 7 & Determine HIV Screening tests & 30 & 30 & \\
\hline 10 & Malaria Rapid Diagnostic tests & 3 & 10 & \\
\hline 21 & Nevirapine (NVP) 50mg & 3 & 10 & \\
\hline 22 & Cotrimoxazole $960 \mathrm{mg}$ tablet & 30 & 30 & Vital \\
\hline 28 & Ceftriaxone $1 \mathrm{~g}$ Injection & 1 & 10 & Vital \\
\hline 46 & Iron & 270 & 300 & Essential \\
\hline 100 & Pregnancy test strips 50 strips & 100 & 100 & \\
\hline 346 & Erythromycin tablets bp 250mg & 120 & 120 & Vital \\
\hline 353 & Etonogestrel 150 mg implant (implanon) & 1 & 10 & Vital \\
\hline 357 & Lamivudine, Zidovudine and Nevirapine tablets & $\begin{array}{c}147 \\
0\end{array}$ & 1500 & \\
\hline 360 & $\begin{array}{l}\text { Efavirez, Lamuvidine, Torofoir, Disoproxil, } \\
\text { Fumarate } 600 / 300 / 300 \mathrm{mg}\end{array}$ & $\begin{array}{c}175 \\
0\end{array}$ & 1800 & \\
\hline 365 & Multivitamin tablets & 120 & 120 & Necessary \\
\hline $339-1$ & Doxycycline capsules $100 \mathrm{mg}$ & 80 & 80 & Vital \\
\hline $339-2$ & CANNULA I.V, 20G. 0.9MM & 36 & 40 & Essential \\
\hline
\end{tabular}

Table 4. Type 1 item prediction result 


\begin{tabular}{cllll}
\hline Item ID & Item Name & $\begin{array}{l}\text { Actual } \\
\text { Demand }\end{array}$ & $\begin{array}{l}\text { Predictive } \\
\text { Demand }\end{array}$ & Ven Scale \\
\hline 3 & Co-tromoxazole 480mg tablet & 250 & 285 & Vital \\
\hline 15 & Zidovudine /Lamivudine/Nevirapine & 215 & 210 & \\
\hline 44 & Folic Acid & 600 & 620 & Essential \\
\hline 347 & Amoxicilin Capsules & 25 & 30 & Vital \\
\hline 349 & Metronidazole tablets & 60 & 75 & Vital \\
\hline
\end{tabular}

Table 5. Type 2 item prediction result

For type 3 products, double exponential smoothing method were applied to predict the future demands as the consumption information is sufficient to capture the demand fluctuation as well. Double exponential smoothing is a time series forecasting method for univariate data that can be extended to support data with a systematic trend or seasonal component. To obtain the best double exponential smoothing model in time series prediction, trial and error tests were conducted to select the combinations of smoothing constants (alpha value and gamma value) with least mean absolute percentage error (MAPE) and median absolute deviation (MAD) in model prediction.

From the collected data, it was discovered that only three items (Sulfadoxine/Pyrimethamine tablet, Tenofovir/Lamivudine/Efavirenz tablet and Cotrimoxazole tablet) have sufficient information in applying double exponential smoothing method for next three to six months demand prediction. The preliminary trends of demand prediction can be shown on Fig. 8-10.

The demand pattern of Sulfadoxine/Pyrimethamine tablets were found to have less apparent trend compared to the other two products. From the fitting line generated by the double exponential smoothing method, the model could not capture the abrupt quantity increase or decrease very well. In this perspective, we can infer a double exponential smoothing model works better in the prediction of the items with apparent trend and less demand fluctuation. Despite the model not being able to capture the demand pattern effectively, this model has relatively good accuracy measures compared to another smoothing constant combination. The demand forecast trend developed has shown that the demand quantity of Sulfadoxine/Pyrimethamine tablets will be decreased in the next three months. Different from Sulfadoxine/Pyrimethamine, the fitting lines of the other two supplies (Tenofovir/Lamivudine/Efavirenz tablet and Cotrimoxazole tablet) have better performance in capturing the future demand trend because the consumption data have apparent trend. The prediction results show that the demand of Tenofovir/Lamivudine/Efavirenz in the next three months will increase slightly and that of Cotrimoxazole will decrease slightly.

In summary, the forecasted results indicated that, based on the data collected by the implemented system, the future demands can be forecasted according to the type of demand. However, the proposed approach has some limitations. First, the accuracy of forecasted demands largely depends on the amount of consumption data collected by the system. Additionally, the suggestion system for procurement based on the forecasted demand in real time has not been 
addressed. Thus, in order to increase the accuracy of prediction, we will keep track of demand changes and utilize the forecasted demands to provide more sophisticated order suggestions.

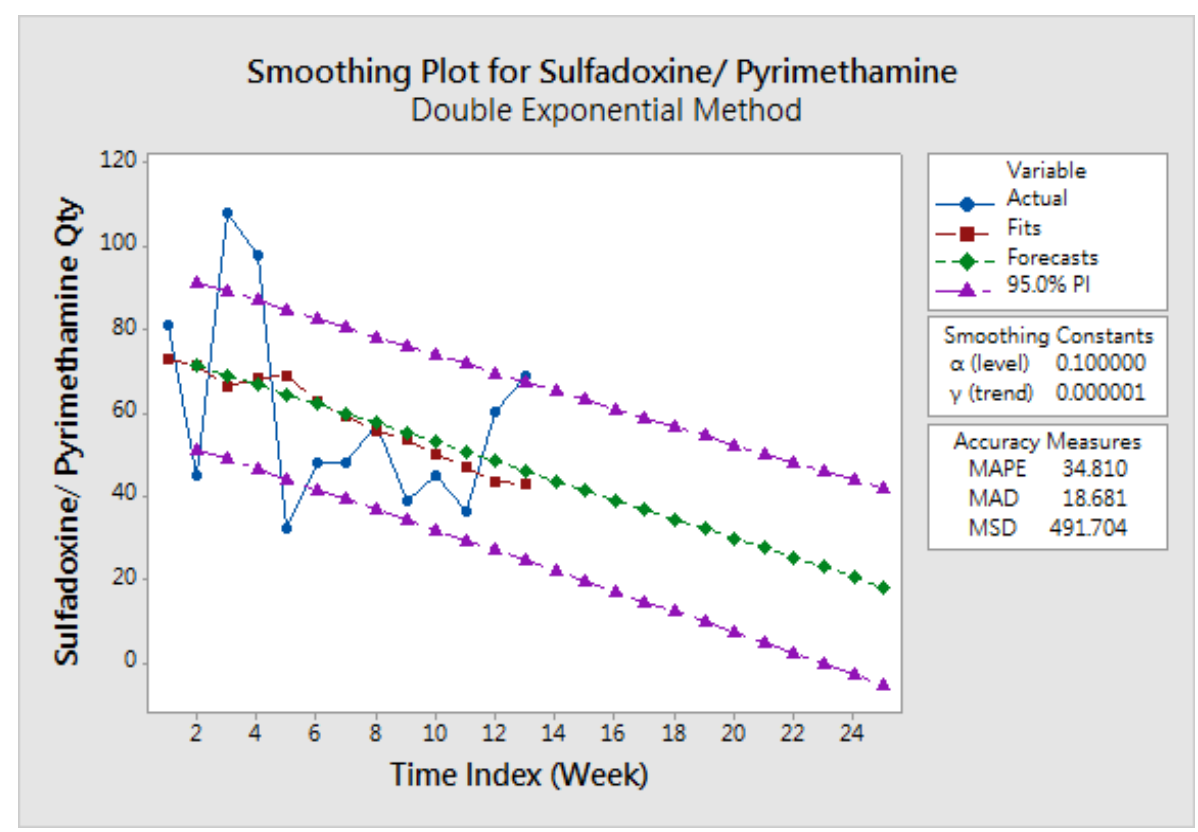

Fig. 8 Demand prediction for Sulfadoxine/ Pyrimethamine tablet

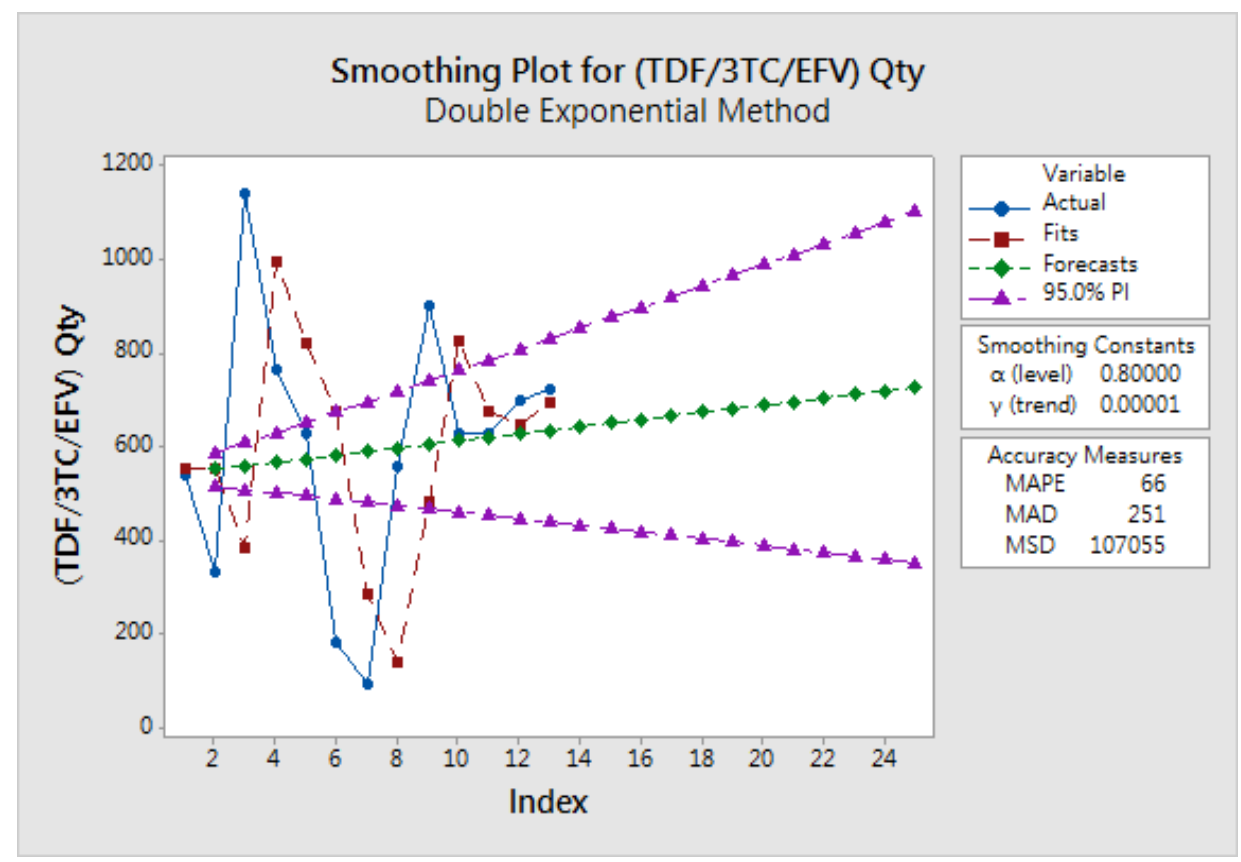

Fig. 9 Demand prediction for Tenofovir/Lamivudine/Efavirenz tablet 


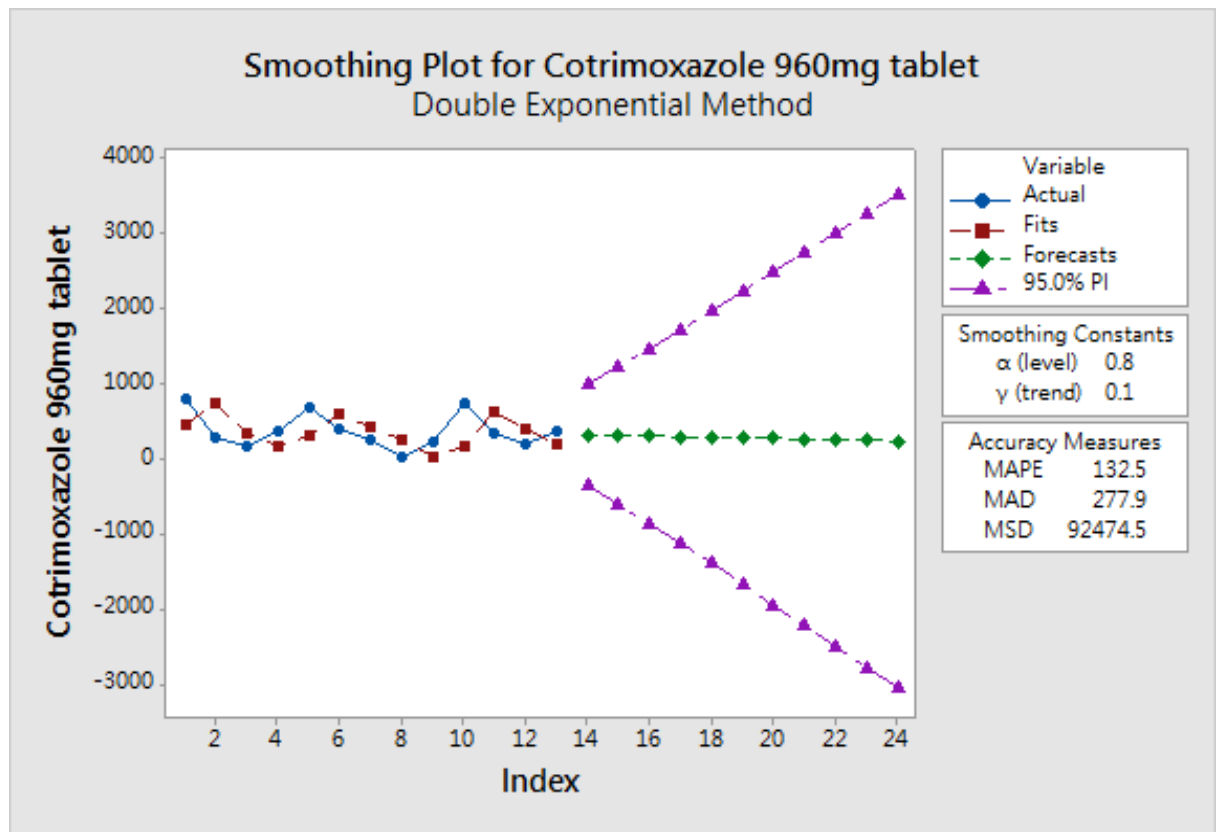

Fig. 10 Demand prediction for Cotrimoxazole tablet

\section{Discussion}

\section{Healthcare Workflow}

The district medical store receives health products (medicines, supplies and laboratory reagents) every 2 months from National Medical Store (NMS) according to a predefined schedule for the six cycles of the year and stores them temporarily, for few days until they are distributed to health facilities in with $3 \sim 4$ days after receipt. The products delivered to the district medical store are already earmarked to each of the health facilities. A private contractor, called 3-ways, picks the products from the district medical store and delivers them to each of the health facilities in the district. At the facility, the storekeepers/managers receive the products and accompanying documents (delivery notes and invoices). The physical type, count, expiry dates and other physical features are checked against the delivery notes and invoice. If there is any discrepancy, discrepancy form is filled out and signed by all the parties concerned. The delivery of the products happens in the presence of a representative from council and health unit management committee. In general products are short delivered compared to cyclic orders both in type and quantity. The estimated annual discrepancy between total value of order and supply for the year 2016 was $20-30 \%$. We observed multiple multiples issues in the overall process:

- The storekeepers/lab managers order just based on their experience and many times that estimation is incorrect resulting in overstock or understock.

- Once received, there is no mechanism to receive the supplies for understock items until the next cycle is due.

- It takes multiple days for the storekeeper to update all the stock cards.

- There is no existing mechanism to communicate among health facilities below level IV to exchange overstock supplies.

- A tool for tracking unused money is highly preferred. Each of the health facilities has its own allocated money that is given to NMS at the beginning of the financial year. But 
when they fail to provide any commodity, it does not show the amount of unused money to the district offices or health facilities. The importance of a tool that can track

expenditure and compare with the initial budget to calculate the balance remaining at the time of delivery of products was recommended.

- There is a big gap in the annual budget for medicines and supplies (does not include laboratory reagents and supplies). In Kojja Health center IV, the budget was 52 million Shilling/year which is roughly $38 \%$ of the actual need. In this scenario quantification is one of the biggest challenges. The storekeeper needs to make a judgement call regarding how much to order for each essential commodity within this limited budget.

\section{Stakeholder Engagement Process}

Securing early buy-in from MOH is very important. The Ministry has a number of bureaucratic channels and levels through which the necessary buy-in can be obtained. The earliest level for buy-in is at the 'user' department or unit who are the potential users of the innovation. Typically, a department to which the proposed innovation speaks. The department assigns a focal person who should understand how the innovation works. This focal point is supposed to handhold the innovation team to navigate the next level of buy-in. This involves a series of pitches to the Ministry's Technical Working Groups (TWGs).

1. The first pitch at a user (beneficiary) technical department level TWG, in our case the MCH TWG. The TWG makes an endorsement indicating ownership of the innovation and recommends to the next level of approval, which is e-Health TWG.

2. E-Health TWG coordinates and approves all innovations that are piloted within the $\mathrm{MOH}$ infrastructure and system. The e-Health TWG vets the proposed innovation and how the innovation will support the work of the user technical department. This TWG thereafter makes approval for innovation pilot and testing within the Ministry.

While $\mathrm{MOH}$ has been championing for a migration from paper-based system to electronic system, there is still a long way to go. The Ministry has a number of e-health systems that have been piloted, and some scaled. However, there is still a large reliance on paper-based systems to collect and report routine data including HMIS data.

The health workers at both Kojja and Mukono where the innovation was piloted exhibited large interests and enthusiasm. The use of portable tablets was new to them. The health workers had been accustomed to collecting routine data using paper-based HMIS forms.

Incentives in the form of allowances to the health workers and volunteer research assistants were key for data collection to proceed. Health workers were involved in multiple activities within their respective departments, and as such, the allowances did incentivize them to take on what they perceived as an extra task.

Infrastructure was unreliable at both Kojja and Mukono, frequently suffering from power outages. At the time of our pilot, there was a power line replacement that took about 3 months. We also faced challenges of setting up an intranet within both facilities. The departments to which services are delivered, $\mathrm{MCH}$, Lab, store and dispensary, are detached from each other. Health services were not under a single building but rather multiple isolated buildings that are scattered several meters apart. Setting up an effective intranet was a challenge right from the start of the pilot. 
This system only covers $\mathrm{MCH}$ now. More departments must be covered, including services given to mothers in the Out-Patient Department (OPD) to make accountability for OPD supplies possible.

\section{Conclusions}

We designed a cloud-based, multi-platform, centralized, offline-compatible healthcare supply chain management system tailored for $\mathrm{MCH}$. It is capable of triangulating supply and demand data from three different departments (main store, lab, and $\mathrm{MCH}$ ) to forecast and generate orders automatically to meet patient demands. It is capable of generating reports required by $\mathrm{MOH}$ in real time compared to one-week lead-time using paper-based systems. This prompts frontline stakeholders to generate efficient, reliable and sustainable strategic healthcare plans with real time data. This system improves patient outcomes through better commodity availability by sensing true patient demands.

This system is designed for intermittent internet connectivity. For daily operation, it operates without internet. When online, the system provides additional features such as backups, updates, and remote diagnosis/troubleshooting. As infrastructure improves and internet connectivity becomes more continuous, the system provides real-time monitoring and visibility of inventory levels, improving coordination and strategic planning among facilities locally, regionally and nationally.

\section{List of Abbreviations}

E+TRA Health: Electronic tracking system for healthcare commodities; MCH: Maternal Child Health; MOH: Ministry of Health; SCM: healthcare supply chain management; EMR: electronic medical record; UN: United Nations; VHTs: Village Health Teams; HIS: Health Information System; HMIS: health management information system; DHO: District Health Office; HIV: human immunodeficiency virus; ERT: Embedded Research Translation; IKT: Integrated Knowledge Translation; CIHR: Canadian Institute of Health Research; RAN: Resilient Africa Network; TWGs: Ministry's Technical Working Groups; OPD: Out-Patient Department; MAPE: mean absolute percentage error; MAD: median absolute deviation; NRHs: National Referral Hospitals; RRHs: Regional Referral Hospitals; HC: Health Center

\section{Declarations}

\section{Ethics approval and consent to participate}

Not applicable

\section{Consent for publication}

Not applicable

\section{Availability of data and materials}

Not applicable

\section{Competing interests}

The authors declare that they have no competing interests.

\section{Funding}


This project is supported, in part, by the Bill and Melinda Gates Foundation OPP1181795, and Regenstrief Center for Healthcare Engineering at Purdue University.

\section{Authors' contributions}

DW, RK, SJ, MH, and YY designed the workflow and the system. JS, RM and AO provided expert advice from the perspective of a medical professional. DW, RK, SJ coded the system. JS, RM engaged with $\mathrm{MOH}$, selected the sites, and engaged with health center practitioners. JS, YY, $\mathrm{MH}, \mathrm{AO}$ and RM did the initial site evaluation. PB and YY designed the collaborative research approach. DW, YY, JS, RM deployed the system into selected 2 piloting sites. DW, RK and SJ developed the predictive model. SL supervised the design of the predictive model and data analysis. YY supervised the design, development, deployment, data collection and analysis. All authors have read and aided to write the paper and contributed to discussing the results.

\section{Acknowledgements}

We would like to thank Daniel Dilley for editing and improving the manuscript.

\section{Reference}

[1] Say L, Chou D, Gemmill A, Tunçalp Ö, Moller AB, Daniels J, Gülmezoglu AM, Temmerman M, Alkema L. Global causes of maternal death: a WHO systematic analysis. The Lancet Global Health. 2014 Jun 1;2(6):e323-33.

[2] Ronsmans C, Graham WJ, Lancet Maternal Survival Series steering group. Maternal mortality: who, when, where, and why. The lancet. 2006 Sep 30;368(9542):1189-200.

[3] Tort J, Rozenberg P, Traoré M, Fournier P, Dumont A. Factors associated with postpartum hemorrhage maternal death in referral hospitals in Senegal and Mali: a crosssectional epidemiological survey. BMC pregnancy and childbirth. 2015 Dec 1;15(1):235.

[4] Mbonye AK. Risk factors associated with maternal deaths in health units in Uganda. African Journal of Reproductive Health. 2001 Dec 1:47-53.

[5] Mbonye AK, Mutabazi MG, Asimwe JB, Sentumbwe O, Kabarangira J, Nanda G, Orinda V. Declining maternal mortality ratio in Uganda: priority interventions to achieve the Millennium Development Goal. International Journal of Gynecology \& Obstetrics. 2007 Sep 1;98(3):285-90.

[6] Jonathan HG, Stoltenberg RH. UN commission on life-saving commodities for women and children. New York: United Nations. 2012.

[7] Yadav P. Health product supply chains in developing countries: diagnosis of the root causes of underperformance and an agenda for reform. Health Systems \& Reform. 2015 Feb $17 ; 1(2): 142-54$.

[8] Kiberu VM, Matovu JK, Makumbi F, Kyozira C, Mukooyo E, Wanyenze RK.

Strengthening district-based health reporting through the district health management information software system: the Ugandan experience. BMC medical informatics and decision making. 2014 Dec;14(1):1-9.

[9] Olok GT, Yagos WO, Ovuga E. Knowledge and attitudes of doctors towards e-health use in healthcare delivery in government and private hospitals in Northern Uganda: a cross-sectional study. BMC medical informatics and decision making. 2015 Dec 1;15(1):87. 
[10] Liang L, Wiens MO, Lubega P, Spillman I, Mugisha S. A Locally Developed Electronic Health Platform in Uganda: Development and Implementation of Stre@ mline. JMIR formative research. 2018;2(2):e20.

[11] MOH. Health sector strategic \& investment plan: promoting people's health to enhance socio-economic development title. http://www.health.go.ug/docs/HSSIP10.pdf. Accessed 15 Dec 2020 .

[12] Landén EN, MHealth systems, Transformations in Work and Implications for Sustainability. PhD thesis. University of Oslo. 2019 Jan. https://www.mn.uio.no/ifi/english/research/networks/hisp/research-library/thesis/esther.pdf. Access 15 Dec 2020.

[13] Gladwin J, Dixon RA, Wilson TD. Implementing a new health management information system in Uganda. Health policy and planning. 2003 Jun 1;18(2):214-24.

[14] Kintu P, Nanyunja M, Nzabanita A, Magoola R. DEVELOPMENT OF HMIS IN POOR COUNTRIES: UGANDA AS A CASE STUDY. health policy and development. UMU Press. 2005;3(01):46-53.

[15] Jawhari B, Ludwick D, Keenan L, Zakus D, Hayward R. Benefits and challenges of EMR implementations in low resource settings: a state-of-the-art review. BMC medical informatics and decision making. 2016 Dec;16(1):116.

[16] Boonstra A, Versluis A, Vos JF. Implementing electronic health records in hospitals: a systematic literature review. BMC health services research. 2014 Dec 1;14(1):370.

[17] Fraser H, Biondich P, Moodley D, Choi S, Mamlin B, Szolovits P. Implementing electronic medical record systems in developing countries. Journal of Innovation in Health Informatics. 2005;13(2):83-95.

[18] Williams F, Boren S. The role of the electronic medical record (EMR) in care delivery development in developing countries: a systematic review. Journal of Innovation in Health Informatics. 2008;16(2):139-45.

[19] Chib A, van Velthoven MH, Car J. mHealth adoption in low-resource environments: a review of the use of mobile healthcare in developing countries. Journal of health communication. 2015 Jan 2;20(1):4-34.

[20] Beratarrechea A, Lee AG, Willner JM, Jahangir E, Ciapponi A, Rubinstein A. The impact of mobile health interventions on chronic disease outcomes in developing countries: a systematic review. Telemedicine and e-Health. 2014 Jan 1;20(1):75-82.

[21] Antao VC, Pinheiro GA. Surveillance for occupational respiratory diseases in developing countries. InSeminars in respiratory and critical care medicine 2015 Jun (Vol. 36, No. 3, p. 449). NIH Public Access.

[22] Nsubuga P, Nwanyanwu O, Nkengasong JN, Mukanga D, Trostle M. Strengthening public health surveillance and response using the health systems strengthening agenda in developing countries. BMC public health. 2010 Dec;10(1):1-5.

[23] Haskew J, Turner K, Rø G, Ho A, Kimanga D, Sharif S. Stage of HIV presentation at initial clinic visit following a community-based HIV testing campaign in rural Kenya. BMC public health. 2015 Dec 1;15(1):16. 
[24] Blaya JA, Cohen T, Rodríguez P, Kim J, Fraser HS. Personal digital assistants to collect tuberculosis bacteriology data in Peru reduce delays, errors, and workload, and are acceptable to users: cluster randomized controlled trial. International Journal of Infectious Diseases. 2009 May 1;13(3):410-8.

[25] Fraser HS, Jazayeri D, Nevil P, Karacaoglu Y, Farmer PE, Lyon E, Fawzi MK, Leandre F, Choi SS, Mukherjee JS. An information system and medical record to support HIV treatment in rural Haiti. Bmj. 2004 Nov 11;329(7475):1142-6.

[26] Were MC, Shen C, Bwana M, Emenyonu N, Musinguzi N, Nkuyahaga F, Kembabazi A, Tierney WM. Creation and evaluation of EMR-based paper clinical summaries to support HIVcare in Uganda, Africa. International journal of medical informatics. $2010 \mathrm{Feb}$ 1;79(2):90-6.

[27] Tweya H, Feldacker C, Haddad LB, Munthali C, Bwanali M, Speight C, Kachere LG, Tembo P, Phiri S. Integrating family planning services into HIV care: use of a point-of-care electronic medical record system in Lilongwe, Malawi. Global health action. 2017 Jan $1 ; 10(1): 1383724$.

[28] Haskew J, Rø G, Saito K, Turner K, Odhiambo G, Wamae A, Sharif S, Sugishita T. Implementation of a cloud-based electronic medical record for maternal and child health in rural Kenya. International journal of medical informatics. 2015 May 1;84(5):349-54.

[29] Kiberu VM, Mars M, Scott RE. Barriers and opportunities to implementation of sustainable e-Health programmes in Uganda: A literature review. African journal of primary health care \& family medicine. 2017;9(1):1-0.

[30] Tukamuhabwa B, Stevenson M, Busby J. Supply chain resilience in a developing country context: a case study on the interconnectedness of threats, strategies and outcomes. Supply Chain Management: An International Journal. 2017 Sep 11.

[31] Madinah N. Challenges and barriers to the health service delivery system in Uganda. IOSR Journal of Nursing and Health Science. 2016;5(2):30-8.

[32] Graham ID, Kothari A, McCutcheon C. Moving knowledge into action for more effective practice, programmes and policy: protocol for a research programme on integrated knowledge translation. Implementation Science. 2018 Dec 1;13(1):22.

[33] Kreindler SA. Advancing the evaluation of integrated knowledge translation. Health research policy and systems. 2018 Dec 1;16(1):104.

[34] Kothari A, Wathen CN. A critical second look at integrated knowledge translation. Health Policy. 2013 Feb 1;109(2):187-91.

[35] Walton K, Ambrose T, Annis A, Ma DW, Haines J. Putting family into family-based obesity prevention: enhancing participant engagement through a novel integrated knowledge translation strategy. BMC medical research methodology. 2018 Dec 1;18(1):126.

[36] McIsaac JL, Penney TL, Storey KE, Sigfridson L, Cunningham J, Kuhle S, Kirk SF. Integrated knowledge translation in population health intervention research: a case study of implementation and outcomes from a school-based project. Health Research Policy and Systems. 2018 Dec 1;16(1):72.

[37] Gagliardi AR, Dobrow MJ. Identifying the conditions needed for integrated knowledge translation (IKT) in health care organizations: qualitative interviews with researchers and 
research users. BMC health services research. 2016 Dec 1;16(1):256.

[38] Roberge-Dao J, Yardley B, Menon A, Halle MC, Maman J, Ahmed S, Thomas A. A mixedmethods approach to understanding partnership experiences and outcomes of projects from an integrated knowledge translation funding model in rehabilitation. BMC health services research. 2019 Dec 1;19(1):230.

[39] Web Technology Surveys. Usage of server-side programming languages for websites. https://w3techs.com/technologies/overview/programming_language. 15 Dec 2020.

[40] Asay M. Php and perl crashing the enterprise party. Feb 2010.

https://www.cnet.com/news/php-and-perl-crashing-the-enterprise-party/. 15 Dec 2020. 
Figures

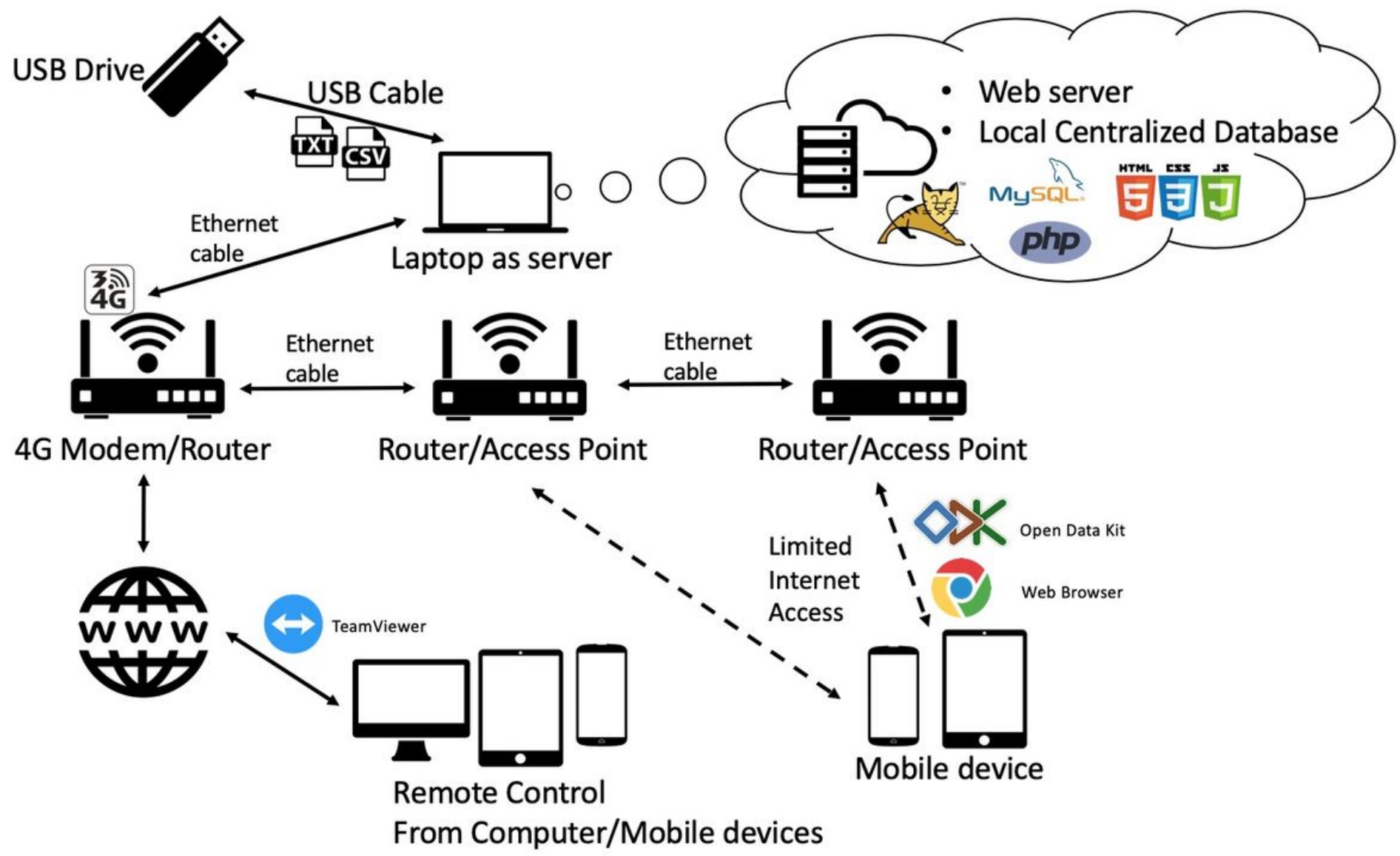

Figure 1

Architecture 
* The date to fill the form

Oct 08, 2019, 22:30

* Patient ID

* Tetanus Dose Given

* IPT/CTX

* Menbendazole-Dose

* IRON Provided

* Vitamin A Supplementation Provided

\section{Go Up}

Figure 2

Example mobile device form 
HMIS FORM 072a: MATERNITY TALLY SHEET

Report for 03-2019

\begin{tabular}{|c|c|}
\hline \multicolumn{2}{|l|}{ ADMISSIONS } \\
\hline ADMISSIONS & 68 \\
\hline \multicolumn{2}{|l|}{ REFERRALS } \\
\hline REFERRALS TO MATERNITY UNIT & 0 \\
\hline REFERRALS OUT FROM THE MATERNITY UNIT & 0 \\
\hline \multicolumn{2}{|l|}{ DELIVERIES IN UNIT } \\
\hline DELIVERIES IN UNIT AMONG THE WOMEN AGED 10-19 YEARS & 2 \\
\hline DELIVERIES IN UNIT AMONG THE WOMEN AGED 20-24 YEARS & 5 \\
\hline DELIVERIES IN UNIT AMONG THE WOMEN AGED > $>25$ YEARS & 6 \\
\hline FRESH STILL BIRTH & 0 \\
\hline MACERATED STILL BIRTH & 0 \\
\hline LIVE BIRTHS & 13 \\
\hline \multicolumn{2}{|l|}{ WOMEN TESTED FOR HIV IN LABOUR } \\
\hline WOMEN TESTED FOR HIV IN LABOUR FOR THE 1ST TIME PREGNANCY & 10 \\
\hline WOMEN TESTED FOR HIV IN LABOUR DURING A RETEST THIS PREGNANCY & 0 \\
\hline WOMEN TESTING HIV+ IN LABOUR FOR THE 1ST TIME PREGNANCY & 0 \\
\hline WOMEN TESTING HIV+ IN LABOUR DURING A RETEST THIS PREGNANCY & 0 \\
\hline \multicolumn{2}{|l|}{ HIV+ WOMEN INITIATING ART IN MATERNITY } \\
\hline HIV+ WOMEN INITIATING ART IN MATERNITY & 0 \\
\hline \multicolumn{2}{|l|}{ DELIVERIES TO HIV+ WOMEN IN UNIT } \\
\hline DELIVERIES TO HIV+ WOMEN IN UNIT & 2 \\
\hline LIVE BIRTHS TO HIV+ WOMEN IN UNIT & 2 \\
\hline \multicolumn{2}{|l|}{ HIV-EXPOSED BABIES GIVEN ARVS } \\
\hline HIV-EXPOSED BABIES GIVEN ARVS & 2 \\
\hline \multicolumn{2}{|l|}{$\begin{array}{l}\text { MOTHERS WHO INITIATED BREASTFEEDING WITHIN THE FIRST HOUR } \\
\text { AFTER DELIVERY }\end{array}$} \\
\hline $\begin{array}{l}\text { TOTAL NO. OF MOTHERS WHO INITIATED BREASTFEEDING WITHIN THE FIRST } \\
\text { HOUR AFTER DELIVERY }\end{array}$ & 13 \\
\hline $\begin{array}{l}\text { NO. OF HIV+ MOTHERS WHO INITIATED BREASTFEEDING WITHIN THE FIRST } \\
\text { HOUR AFTER DELIVERY }\end{array}$ & 2 \\
\hline \multicolumn{2}{|l|}{ BABIES BORN WITH LOW BIRTH WEIGHT ( $<2.5 \mathrm{KG})$} \\
\hline BABIES BORN WITH LOW BIRTH WEIGHT (<2.5KG) & 0 \\
\hline \multicolumn{2}{|l|}{ LIVE BABIES } \\
\hline LIVE BABIES & 13 \\
\hline \multicolumn{2}{|l|}{ BABIES BORN WITH DEFECT } \\
\hline BABIES BORN WITH DEFECT & 0 \\
\hline \multicolumn{2}{|l|}{ MOTHERS GIVEN VITAMIN A SUPPLEMENTATION } \\
\hline MOTHERS GIVEN VITAMIN A SUPPLEMENTATION & 0 \\
\hline \multicolumn{2}{|l|}{ MATERNAL DEATHS IN WOMEN } \\
\hline MATERNAL DEATHS IN WOMEN AGED 10-19 YEARS & 0 \\
\hline MATERNAL DEATHS IN WOMEN AGED 20-24 YEARS & 0 \\
\hline MATERNAL DEATHS IN WOMEN AGED $>=25$ YEARS & 0 \\
\hline \multicolumn{2}{|l|}{ BORN BEFORE ARRIVAL (BBA) } \\
\hline BORN BEFORE ARRIVAL (BBA) ALIVE & 0 \\
\hline BORN BEFORE ARRIVAL (BBA) DEAD & 0 \\
\hline
\end{tabular}

Figure 3

Generated HMIS printable form 

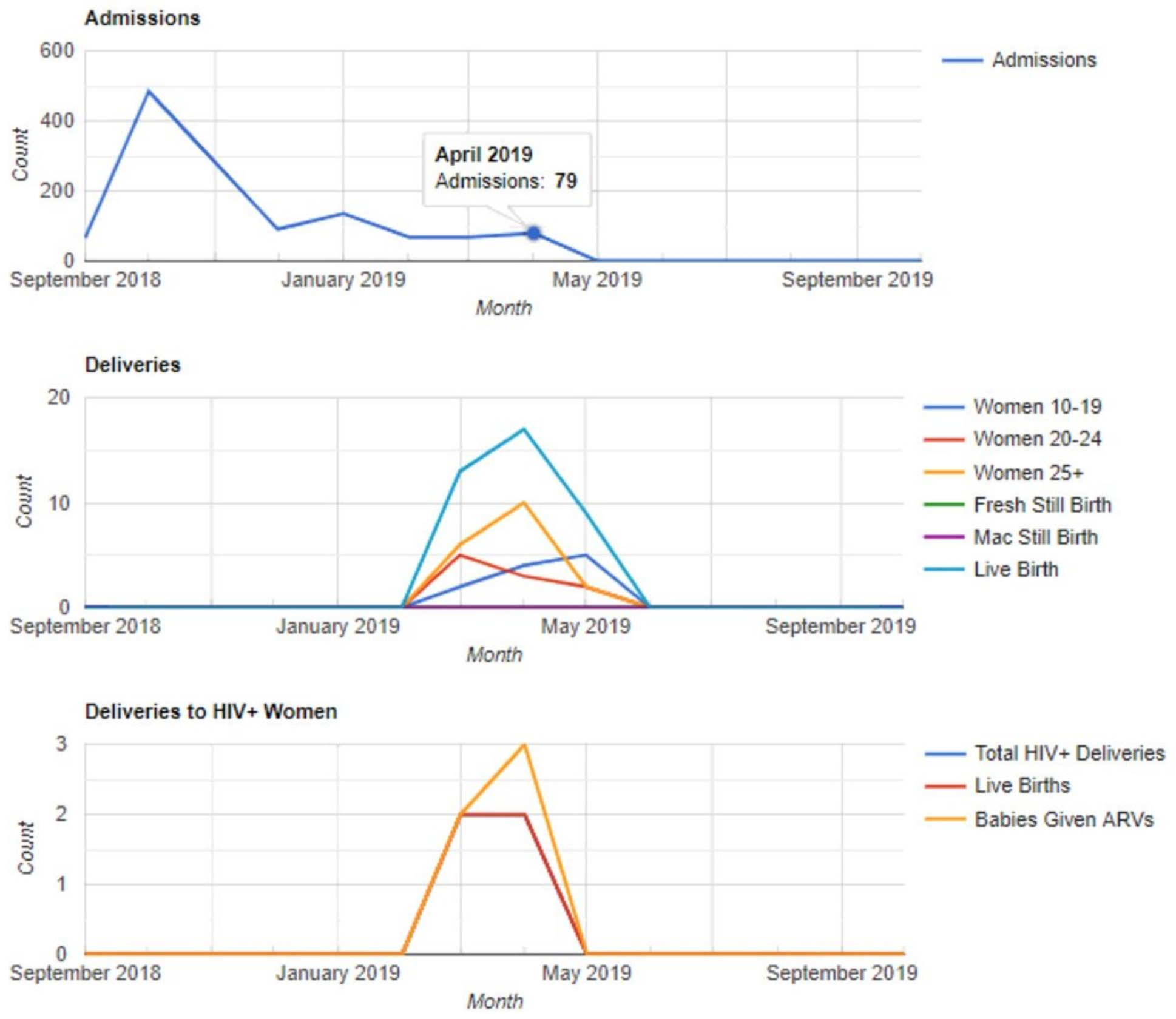

\section{Figure 4}

Generated plots 


\section{Overview of Stocks for multivitamin tablets}

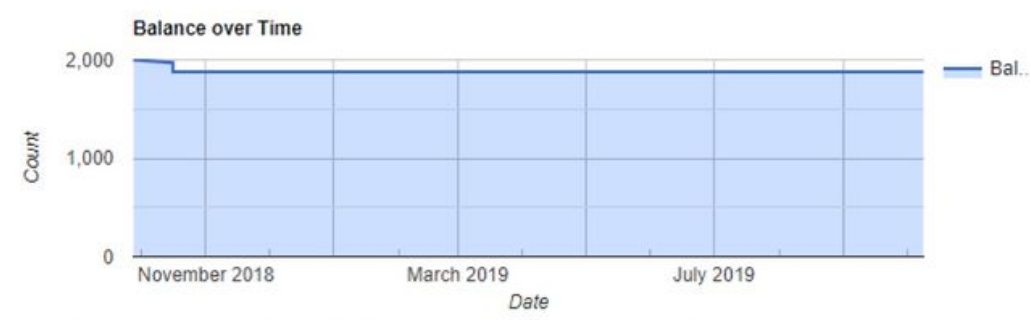

\begin{tabular}{|c|c|c|c|r|}
\hline LOG & MOVEMENT & BALANCE & FORM & DATE \\
\hline 177 & 30 & 1880 & MCH_REGISTER & $2018-10-1607: 44: 00.000000$ \\
\hline 170 & 30 & 1910 & MCH_REGISTER & $2018-10-1607: 38: 00.000000$ \\
\hline 169 & 30 & 1940 & MCH_REGISTER & $2018-10-1607: 34: 00.000000$ \\
\hline 166 & 30 & 1970 & MCH_REGISTER & $2018-10-1607: 31: 00.000000$ \\
\hline 43 & 2000 & 2000 & Manual Addition & $2018-09-2712: 45: 51.000000$ \\
\hline
\end{tabular}

\section{Figure 5}

Full history of transactions of each commodity 
HMIS FORM 071: INTEGRATED ANTENATAL

REGISTER

COLUMN HEADINGS:

\begin{tabular}{|c|c|c|c|c|c|c|c|c|c|c|c|c|c|c|}
\hline \multirow{3}{*}{$\begin{array}{l}\text { (1) } \\
\text { Serial } \\
\text { No. }\end{array}$} & \multirow{3}{*}{$\begin{array}{c}\text { (2) } \\
\text { Client No. }\end{array}$} & \multirow{3}{*}{$\begin{array}{c}\text { (3) } \\
\text { Name of Client }\end{array}$} & \multirow{3}{*}{$\begin{array}{c}(4) \\
\text { Village } \\
+ \\
\text { Parish }\end{array}$} & \multirow{3}{*}{$\begin{array}{l}\text { (5) } \\
\text { Phone } \\
\text { No. }\end{array}$} & \multirow{2}{*}{\multicolumn{2}{|c|}{$\frac{(6)}{\text { Age }}$}} & \multirow{3}{*}{$\frac{(7)}{\text { ANC Visit }}$} & \multicolumn{2}{|c|}{ (8) } & \multirow{3}{*}{$\begin{array}{c}\text { (9a) } \\
\text { Gestational } \\
\text { Age }\end{array}$} & \multirow{3}{*}{$\begin{array}{c}\text { (9b) } \\
\text { ANC1 } \\
\text { Timing }\end{array}$} & \multirow[b]{3}{*}{ 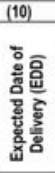 } & \multirow{3}{*}{$\begin{array}{c}\text { (11) } \\
\text { Weight(kg) } \\
\text { MUAC }(\mathrm{cm}) \\
\text { INR no. }\end{array}$} & \multirow{3}{*}{$\begin{array}{c}\text { 12) } \\
\text { Blood } \\
\text { Press } \\
\text { ure }\end{array}$} \\
\hline & & & & & & & & \multirow[t]{2}{*}{ Gravida } & \multirow[t]{2}{*}{ Parity } & & & & & \\
\hline & & & & & 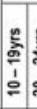 & & & & & & & & & \\
\hline & & Surmante & vinge & & & & & & & & & & menclente & \\
\hline & & & Panes & & & & & & & & & & $\operatorname{sen} \sin ^{2}$ & \\
\hline & & 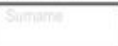 & 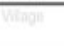 & & & & & & & & & & 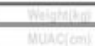 & \\
\hline & & 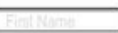 & Pawat & & & & & & & & & & ShR & \\
\hline
\end{tabular}

\begin{tabular}{|c|c|c|c|c|c|c|c|c|c|c|c|c|c|c|}
\hline \multirow{2}{*}{\multicolumn{2}{|c|}{$\begin{array}{l}\text { (13) } \\
\text { EMTCT } \\
\text { codes }\end{array}$}} & \multirow{3}{*}{$\begin{array}{l}\text { (14a) } \\
\text { Diagnosis }\end{array}$} & (14b) & \multirow{3}{*}{$\begin{array}{c}\text { (15) } \\
\text { ARVs } \\
\text { drues } \\
\\
\text { Pre-ART } \\
\text { No. } \\
\end{array}$} & \multirow{3}{*}{\begin{tabular}{|c|} 
(16) \\
$\begin{array}{c}\text { Infant \& Young Child } \\
\text { feeding Counseling } \\
\text { (IYCF) }\end{array}$ \\
$\begin{array}{c}\text { Maternal Nutrition } \\
\text { Counseling }\end{array}$ \\
\end{tabular}} & \multirow{3}{*}{$\frac{(17)}{\text { TB Status }}$} & \multirow{3}{*}{$\begin{array}{c}\text { (18) } \\
\text { Haemoglobin }\end{array}$} & & & (20) & (21) & (22) & (23) & (24) \\
\hline & & & \multirow{2}{*}{$\begin{array}{l}\text { WHO } \\
\text { Winical } \\
\text { Stage /CD4/ } \\
\text { Viral Load }\end{array}$} & & & & & \multicolumn{2}{|c|}{$\begin{array}{l}\text { Syphilis } \\
\text { Test } \\
\text { Results }\end{array}$} & \multirow[t]{2}{*}{$\begin{array}{c}\text { Family } \\
\text { Planning } \\
\text { Counseling }\end{array}$} & \multirow[t]{2}{*}{$\pi$} & \multirow[t]{2}{*}{$\begin{array}{l}\text { IPT/ } \\
\text { CTX }\end{array}$} & \multirow[t]{2}{*}{$\begin{array}{l}\text { Free } \\
\text { win }\end{array}$} & \multirow{2}{*}{ 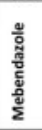 } \\
\hline \multirow[t]{6}{*}{ w } & p & & & & & & & $\mathrm{w}$ & P & & & & & \\
\hline & & & WHOSTAGE & AAV & $\mathrm{BYCF}$ & & & & & & & & & \\
\hline & & & CD48 & & & & & & & & & & & \\
\hline & & & WhOSTAGE & ARV: & IYCE & & & & & & & & & \\
\hline & & & $\cos 4 \pi$ & Prenter & Matemal Nutrition & & & & & & & & & \\
\hline & & & VIRAL LOAR & & Cominceling & & & & & & & & & \\
\hline
\end{tabular}

\begin{tabular}{|c|c|l|l|l|}
\hline \multicolumn{2}{|c|}{ (25) } & \multicolumn{1}{c|}{ (26) } & \multicolumn{1}{c|}{ (28) } \\
\cline { 1 - 2 } \multicolumn{2}{|c|}{ Iron/Folic Acid } & \multirow{2}{*}{ Other Treatments } & Referral In/Out & \multirow{2}{*}{ Risk Factors/Complications } \\
\cline { 1 - 2 } Fe & Folic & & & \\
\hline & & & & \\
\hline & & & & \\
\hline
\end{tabular}

HMIS FORM 072: INTEGRATED MATERNITY REGISTER

HEADINGS AND COLUMN WIDTHS:

\begin{tabular}{|c|c|c|c|c|c|c|c|c|c|c|c|c|c|c|c|c|}
\hline \multicolumn{12}{|c|}{ ADMISSION INF ORMATION } & \multicolumn{5}{|c|}{ DELINERY WFORMATION } \\
\hline (1) & (2) & (3) & (4) & (5) & (6) & (7) & (8) & \multicolumn{2}{|c|}{ (9) } & (10a) & (10b) & (11) & (12) & (13) & (14) & (15) \\
\hline \multirow[t]{2}{*}{ DOA } & $\begin{array}{l}\text { IPO } \\
\text { No }\end{array}$ & $\begin{array}{l}\text { ANC } \\
\text { and } \\
\text { and }\end{array}$ & Name & Village & $\begin{array}{l}\text { Phome } \\
\text { No. }\end{array}$ & Ago & 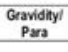 & \multirow[t]{2}{*}{$\begin{array}{l}\text { Woesis of } \\
\text { gestation }\end{array}$} & \multirow[t]{2}{*}{ TIP } & \multirow[t]{2}{*}{$\begin{array}{l}\text { Final } \\
\text { dilignosis }\end{array}$} & \multirow{2}{*}{$\begin{array}{l}\text { WHO } \\
\text { Clinical Stageg/ } \\
\text { CDA Count/ Viral } \\
\text { Load }\end{array}$} & 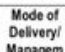 & \multirow{2}{*}{$\begin{array}{l}\text { Dasto of } \\
\text { Deliver } \\
y\end{array}$} & \multirow[t]{2}{*}{$\begin{array}{l}\text { Time of } \\
\text { Dolivery }\end{array}$} & \multirow{2}{*}{$\begin{array}{l}\text { Management } \\
\text { tof } 3 \text { - } \\
\text { Stage }\end{array}$} & \multirow[t]{2}{*}{ Other trostment given } \\
\hline & & $\begin{array}{l}\text { Rot. } \\
\text { No }\end{array}$ & & & & 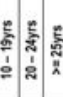 & & & & & & $\begin{array}{l}\text { Mansagem } \\
\text { procecosture }\end{array}$ & & & & \\
\hline & & & nne & & & & & & & & con ons & & & & & \\
\hline
\end{tabular}

\begin{tabular}{|c|c|c|c|c|c|c|c|c|c|c|c|c|c|c|c|c|c|c|c|c|}
\hline \multicolumn{4}{|c|}{ DELUVERY INF ORMATION } & \multicolumn{11}{|c|}{ CHLD INFORMATION } & \multicolumn{6}{|c|}{ DISCHARGE } \\
\hline (16 & & (17) & (18) & (19) & (20) & (21) & (22) & (23) & (24) & 25(a) & 25(0) & (26) & (27) & (28) & (29) & (50) & (31) & (32) & (33) & (B) \\
\hline \multicolumn{2}{|c|}{$\begin{array}{l}\text { emrcr } \\
\text { COOE }\end{array}$} & $\begin{array}{l}\text { ARVs } \\
\text { to } \\
\text { mother }\end{array}$ & $\begin{array}{l}\text { Vitap A } \\
\text { Supplim }\end{array}$ & \multirow{2}{*}{ 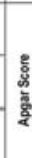 } & \multirow{3}{*}{ Sex } & \multirow{3}{*}{ 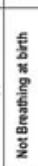 } & \multirow{3}{*}{ 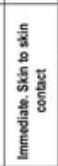 } & \multirow{3}{*}{ 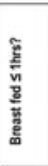 } & \multirow{3}{*}{$\begin{array}{c}\text { Routhen } \\
\text { mesication }\end{array}$} & \multirow{3}{*}{ 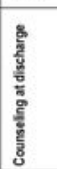 } & \multirow[t]{2}{*}{ IrCF } & \multirow{3}{*}{ WT } & \multirow{3}{*}{$\begin{array}{c}\text { AdAls } \\
\text { adinistered } \\
\text { to baby }\end{array}$} & \multirow{3}{*}{$\begin{array}{l}\text { Immuncizason } \\
\text { BCGFPolio }\end{array}$} & \multirow{3}{*}{$\begin{array}{c}\text { Family } \\
\text { Plumnhy } \\
\text { Manthod } \\
\text { given }\end{array}$} & \multirow{3}{*}{$\begin{array}{l}\text { Condtition } \\
\text { OOMthother } \\
\text { Discharge }\end{array}$} & \multirow{3}{*}{$\begin{array}{c}\text { Condition } \\
\text { of baby } \\
\text { ot } \\
\text { diccharge }\end{array}$} & \multirow{3}{*}{$\begin{array}{c}\text { Dolive } \\
\text { red by }\end{array}$} & \multirow{2}{*}{$\begin{array}{c}\text { PNC at } \\
6 \mathrm{HH}\end{array}$} & \multirow{3}{*}{$\begin{array}{c}\text { Dato of } \\
\text { Dicsharge } \\
\text { Name of } \\
\text { person } \\
\text { dischargin } \\
9\end{array}$} \\
\hline \multirow[t]{5}{*}{ w } & p & ${ }_{A R T}$ & MUAC & & & & & & & & & & & & & & & & & \\
\hline & & & INR no. & & & & & & & & $\begin{array}{c}\text { Irtarm } \\
\text { Fevding } \\
\text { Oop }\end{array}$ & & & & & & & & 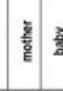 & \\
\hline & & & $\sin A$ & & & & & & & Diech & & & & & & & & & & \\
\hline & & & mence & & & & & & & natith & & & & & & & & & & \\
\hline & & & nethes & & & & & & & & & & & & & & & & & \\
\hline
\end{tabular}

\section{Figure 6}

HMIS Forms: Integrated Antenatal Register and Integrated Maternity Register 
Document Flow Chart for $\mathrm{MCH}$

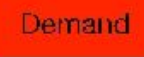

Supply
$\mathrm{MCH}$ Register
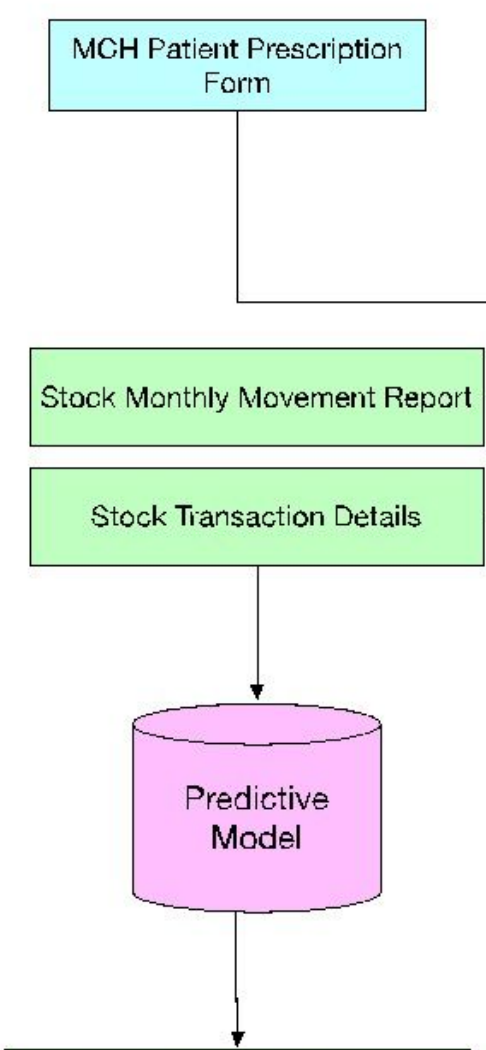

Purchase Order Form
Lab Register

Lab Dispensing Log

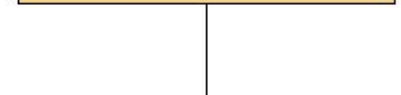

Inventory Manager

Good Delivery Notes

Stock Discrepancy Report

Manual Stock Adjustment

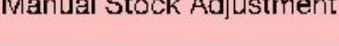

\section{Figure 7}

Document flow for $\mathrm{MCH}$ 


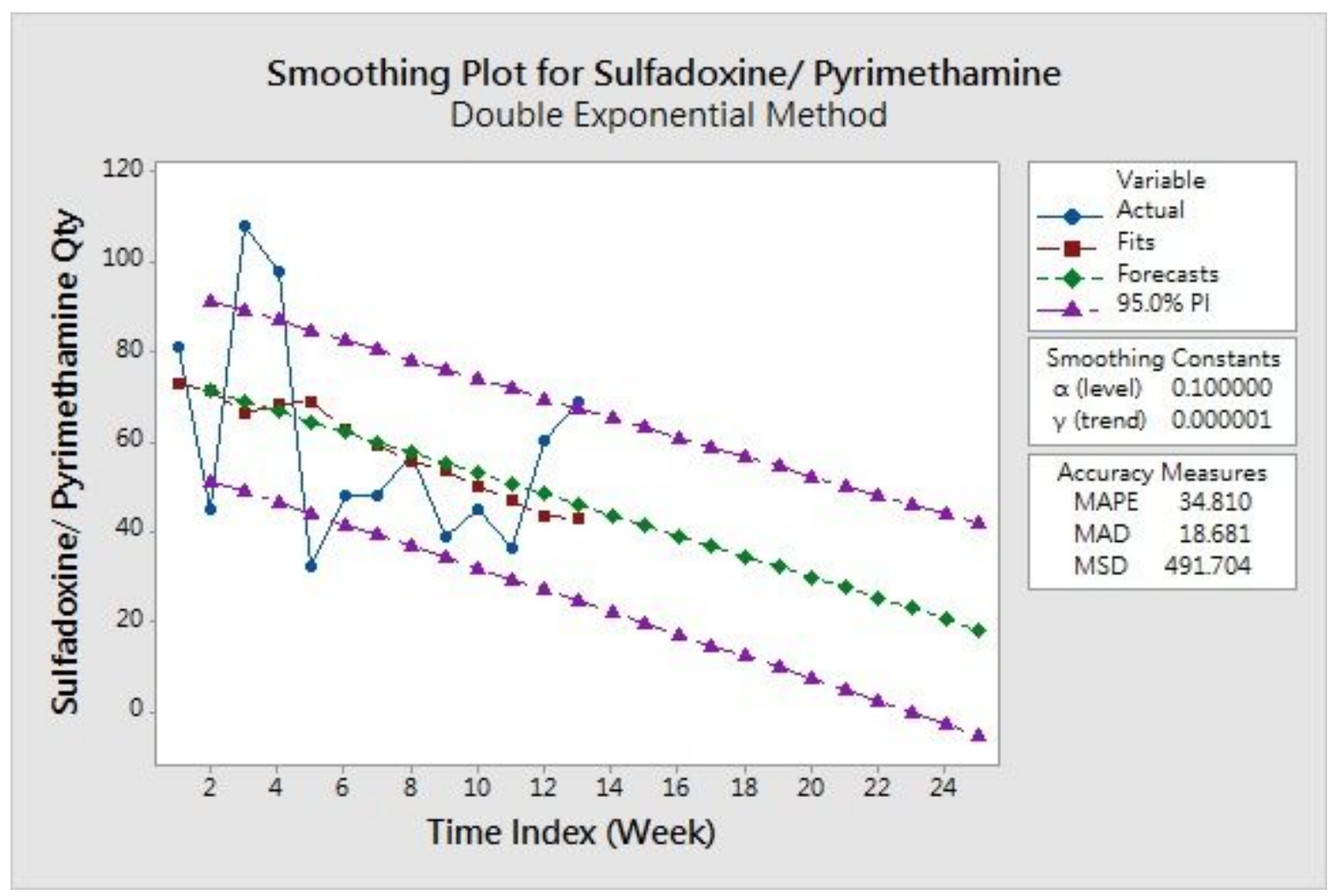

\section{Figure 8}

Demand prediction for Sulfadoxine/ Pyrimethamine tablet

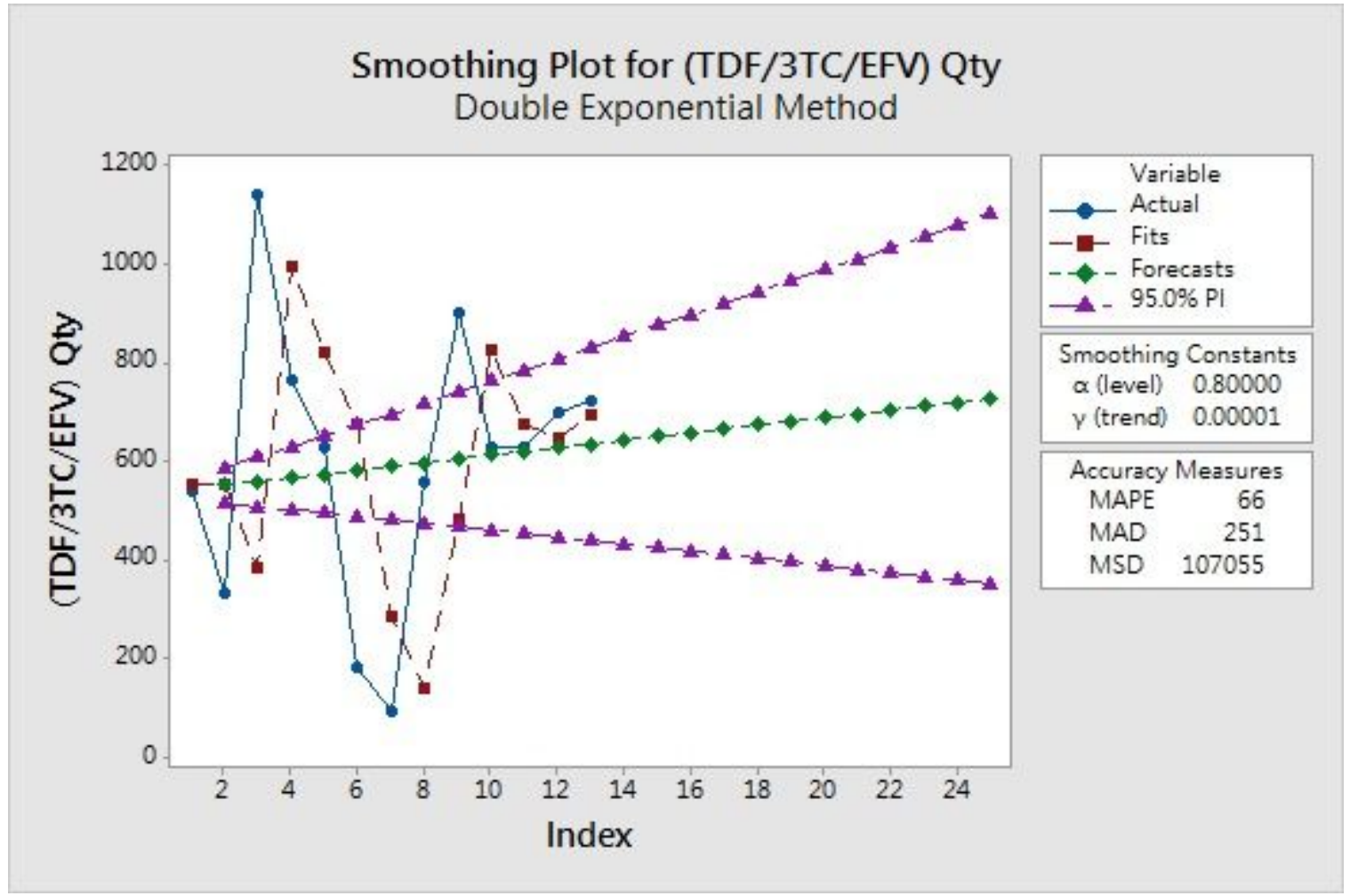

Figure 9

Demand prediction for Tenofovir/Lamivudine/Efavirenz tablet 


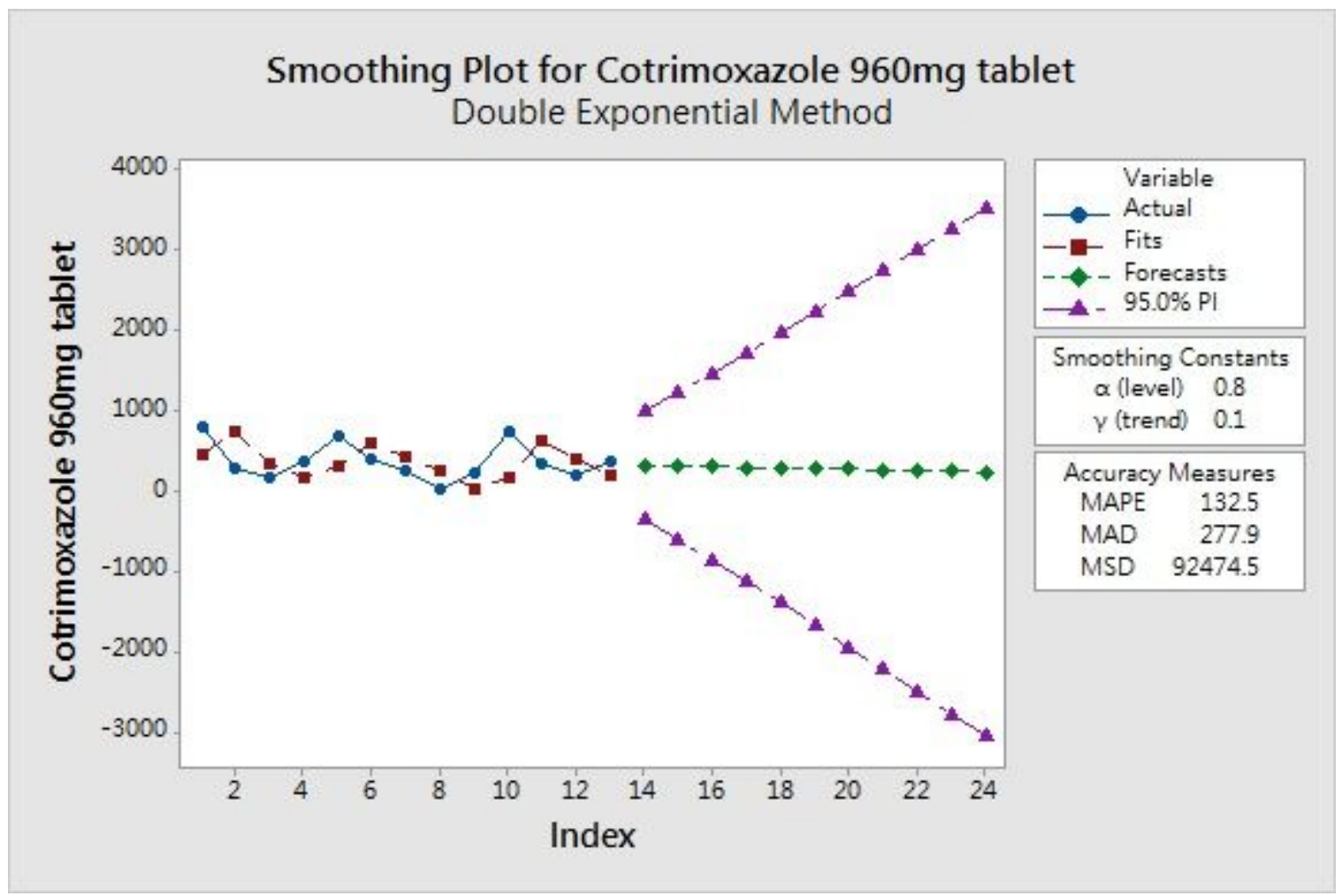

Figure 10

Demand prediction for Cotrimoxazole tablet 